NASA Contractor Report 3072

LOAN COPY $\triangle$ REIERT AFWL TECHMIEALGISUIS

\title{
Prediction and Monitoring
} of Clear Air Turbulence:

\author{
An Evaluation of the Applicability \\ of the Rawinsonde System
}

John L. Keller

CONTRACT NAS8-32111

DECEMBER 1978

\section{N/Sก}

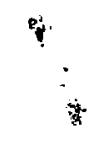


NASA Contractor Report 3072

\section{Prediction and Monitoring} of Clear Air Turbulence:

\section{An Evaluation of the Applicability of the Rawinsonde System}

John L. Keller

University of Dayton Research Institute

Dayton, Obio

Prepared for

George C. Marshall Space Flight Center

under Contract NAS8-32111

\section{N/Sก \\ National Aeronautics \\ and Space Administration}

Scientific and Technical

Information Office 


\section{FOREWORD}

The research reported in this document was motivated by the continuing need for a means of predicting, or at least detecting, Clear Air Turbulence (CAT). Cost factors with respect to the implementation of an operational CAT information system prompted an effort to use the currently available Rawindonde system more objectively than in the past for this purpose. While an unambiguous, unified theory of CAT remains an elusive goal due to the nature of the problem, recent theoretical investigations, albeit idealized, represent further progress toward this end. It is the obligation of the applied scientist to continue to find ways to develop techniques for using these advancements in theoretical CAT research to expedite operational uses. The results contained in this report represent such an effort.

The research was conducted by the University of Dayton Research Institute for the National Aeronautics and Space Administration, Georce G. Marshall Space Flight Center, Huntsville, Alabama, under the technical direction of Mr. Dennis W. Camp of the Space Sciences Laboratory. The support for this effort was provided by Mr. John Enders of the Aviation Safety Technology Branch, Aeronautical Operating Systems Office, Office of Aeronautics and Space Technology. 
TABLE OF CONTENTS

SECTION

PAGE

1 INTRODUCTION

1.1 DISCUSSION OF DATA AND TURBULENCE PARAMETERS

3 THE RAWINSONDE AS A TURBULENCE SENSOR -

INFORMATION FROM VERTICAL WIND PROFILES 19

3.1 DIRECT SENSING OF TURBULENCE 19

3.2 INDIRECT SENSING OF TURBULENCE 21

3.3 RICHARDSON NUMBER 21

3.3.1 Static stability and shear 29

3.3.2 Turbulent structure of Detailed Vertical profiles of the Horizontal Wind 33

3.3.3 The Diagnostic Richardson Number 44

3.4 CONCLUSION $\quad 45$

4 REFERENCES 46 


\section{LIST OF FIGURES}

Figure

Title

Page

1 Correlation diagram showing the Brunt-väisälä frequency squared versus the vector shear amplitude of the horizontal wind

2 Vertical profile of the $\mathrm{Ri}$ number as calculated from the data obtained from the J/J flights of $1345 \mathrm{z} 16$ October 1970

3 Vertical profile of the $\mathrm{Ri}$ as calculated from the data obtained from the $\mathrm{J} / \mathrm{J}$ flight of $1445 \mathrm{Z}$ 18 February 1971

4 The $200 \mathrm{mb}$ constant pressure level chart for 1200216 october 1970. Shown are lines of constant height in decameters ( $10^{1}$ meters) minus $10 \mathrm{Km}$; for example, $188=11880$ meters

5 The $300 \mathrm{mb}$ constant pressure level chart for $1200 \mathrm{z} 18$ February 1971. Shown are lines of constant height in decameters ( 101 meters)

6 The Helmholtz mean velocity profile

7 The CAT mechanism

8 Average spectra of the horizontal wind components in the free atmosphere obtained from numerous aircraft flights; sketched from Vinnichenko and Dutton (1969)

An example of a spectrum of a modeled breaking $\mathrm{K}-\mathrm{H}$ wave sketched from Reiter (1969)

10 The correlation diagram relating the standard deviation of the vertical wind calculated from the filtered $\mathrm{J} / \mathrm{J}$ rise rates, $\sigma_{\mathrm{W}}$, to the $\mathrm{Ri}$

11 The height variation of the horizontal wind measured by the $\mathrm{J} / \mathrm{J}$ system for $1445 \mathrm{Z} 18$ February 1971

12 Vertical variation of the $\mathrm{Ri}$ as calculated for the RW Ilight of $1015 \mathrm{Z} 16$ October 1970

13 Vertical variation of $\mathrm{Ri}$ as calculated for RW flight of $1120 \mathrm{z} 18$ February 1971 
14 Correlation diagram relating the $\mathrm{RW}$ and $\mathrm{J} / \mathrm{J} \mathrm{Ri}$. The range of $\mathrm{Ri}$ was $-1<\mathrm{Ri}<10$ for purposes of illustration

15 The dependence of the ratio of the error in the $\mathrm{Ri}, \varepsilon_{\mathrm{Ri}} / \mathrm{Ri}$, to the number of data points, $N$

16 Correlation diagram comparing RW and $\mathrm{J} / \mathrm{J}$ temperatures at equal Ievels. The correlation coefficient is 0.997

17 Correlation diagram comparing RW and $\mathrm{J} / \mathrm{J}$ horizontal wind amplitudes at equal levels. The correlation coefficient is 0.965

Correlation diagram comparing RW and $\mathrm{J} / \mathrm{J}$ wind direction at equal levels. The correlation coefficient is 0.672

19 Dependence of the natural log of the vector shear amplitude on the interval of calculation for mean extreme shears, mean shears, and smoothed horizontal wind profiles; sketched from Essenwanger and Reiter (1969)

Vertical variation of the vector shear magnitude for the $\mathrm{J} / \mathrm{J}$ flight of $1345 \mathrm{Z} 16$ October 1970

21 Vertical variation of the vector shear magnitude for the RW flight of $1015 \mathrm{Z} 16$ October 1970

Correlation diagram comparing $\mathrm{J} / \mathrm{J}$ and $\mathrm{RW}$ vector shear amplitudes

Vertical variation of the $\mathrm{J} / \mathrm{J}$ vector shear amplitude on the $1445 \mathrm{Z} 18$ February 1971

24 Vertical variation of the RW vector shear amplitude on $1120 \mathrm{z} 18$ February 1971 


\section{LIST OF TABLES}

Table

Title

Page

I

Cape Kennedy Conjunctive Rawinsonde (RW) Jimsphere/ Jimsonde $(J / J)$ Data Summary

II

Definitions of Regions in Figure 22

42

III Summary of RW Shear Layer Sensing Ability and Accuracy Relative to the $\mathrm{J} / \mathrm{J}$ system 
Symbol

$\mathrm{A}_{0}, \mathrm{a}_{0}, \mathrm{~A}_{1}$

$a_{1}$

$c_{p}$

E

g

$\mathrm{H}$

ii

i்

$\mathrm{N}_{\mathrm{B}}$

P

$r$

$\mathrm{Ri}$

$\mathrm{Ri}_{\mathrm{C}}$

$t$

T

$\overline{\mathrm{T}}$

$u$

$\mathrm{U}_{\mathrm{O}}$

v

V

w

$z$

$\gamma$

$\Gamma$
Meaning

Empirical constant fit coefficients

Empirical fit exponent

Specific heat of air at constant pressure

Perturbation energy density

Magnitude of effective gravity

Height of shear layer represented by Helmholtz velocity profile

Unit vector (positive = eastward)

Unit vector (positive = northward)

Brunt-väisälä frequency

Pressure

Correlation coefficient

Richardson number

Critical Richardson number

Time

Temperature

Mean temperature calculated through a layer

Eastward component of wind

Mean wind amplitude

Northward component of wind

Horizontal wind velocity vector

Upward component of wind

Vertical (height) coordinate

Measured temperature lapse rate: $\mathrm{dT} / \mathrm{dz}$

Adiabatic lapse rate: $g / c_{p}$ 
$\Delta$ h Vertical interval of calculation

$|\Delta \mathbb{V}| \quad$ Amplitude of the vertical difference of the horizontal velocity vector

$\Delta \mathbf{z} \quad$ Distance between vertical data points

$\varepsilon_{\mathrm{Ri}} \quad$ Richardson number error

$\Pi,|\Pi|$ Vector shear and vector shear amplitude

$\xi \quad$ Dummy variable

$\rho^{\prime}, \rho_{\mathrm{s}} \quad$ Perturbation and basic state densities

$\sigma_{w} \quad$ Standard deviation of filtered vertical wind component

$\sigma|\Delta V|$ Standard deviation of vertical difference of
horizontal velocity

$\phi \quad$ Horizontal wind direction

The International System of Units (m, $\mathrm{kg}, \mathrm{s},{ }^{\circ} \mathrm{K}$ ) is used throughout, except where otherwise specified. 
Clear Air Turbulence (CAT), according to its strict definition, consists of all turbulent motions in regions of the free atmosphere that are not close to visible convective activity. The important phrase here, as far as commercial aviation is concerned, is "close to visible convective activity", for presumably pilots should be able to avoid many turbulent encounters by steering clear of these regions. Hence, the primary problem would seem to be in locating and forecasting the location of significantly turbulent regions not associated with visible convection.

Airline meteorologists began developing the first CAT "forecasting" techniques in the mid 1950's. Synoptic analysis, plus aircraft reports of CAT encounters were used and through the gradual refinement of the method, the risk of exposure to "severe" CAT was reduced substantially. Nonetheless, it is estimated that the frequency of aircraft encounters of severe CAT is still about forty times per year (Beckwith, 1972). This statistic is a manifestation of the low forecasting skill inherent in qualitative synoptic analysis. In effect, the synoptic scale information obtained by the Rawinsonde (RW) system currently acts merely as a supplement to airline pilot reports.

With the development of the FPS-16 Jimsphere/Jimsonde (J/J) rising balloon system came the capability for obtaining high resolution vertical profiles of certain meteorological variables. Although it appears doubtful that even the $\mathrm{J} / \mathrm{J}$ system can be used as a direct turbulence probe, it does have the ability to accurately detect shear layers of the proper vertical scale; that is, those layers within which a CAT mechanism may be imbedded. It will be shown that this is due to the fact that the J/J system can detect motions at the mesoscale while the RW system cannot. This has important implications in regard to the 
application of the RW system as a single station turbulence sensor - either directly or indirectly.

\subsection{DISCUSSION OF DATA AND .TURBULENCE PARAMETERS}

The data used for the investigation of the feasibility of using the Rawinsonde system for CAT detection were approximately ninety conjunctive $\mathrm{J} / \mathrm{J}$, and $\mathrm{RW}$ soundings made over a period of two years at Cape Kennedy, Florida. The basic meteorological variables are summarized in Table $I$. Several flights were completely eliminated due to bad data. For the statistical comparisons, data above $15 \mathrm{Km}$ and below $4 \mathrm{Km}$ was not used in order to restrict the interpretation of the results to regions of concern to commercial aircraft. The nature of the sensing capabilities of the $J / J$ and RW systems have been discussed in detail in previous reports (e.g., Scoggins, 1967; Fichtl, 1971; Susko and Vaughan, 1968; Range Commanders Council Document $110-77,1977)$.

The basic meteorological variables themselves were subjected to analytical scrutiny and, as well, were used to calculate certain relevant turbulence parameters. The horizontal wind vector is defined as

$$
v=u \ddot{i}+v \ddot{j}
$$

where $i i, \ddot{j}, u$ and $v$ are the eastward and northward unit vectors and wind components, respectively. The vertical temperature gradient $(d T / d z)$ and wind shear components ( $d u / d z$ and $d v / d z$ ) were calculated using a least squares Legendre polynomial linear fit

$$
d \xi_{i} / d z=\frac{\sum_{i=1}^{N} \xi_{i}[(i-1)-(N-1) / 2]}{\left[N\left(N^{2}-1\right) / 12\right] \Delta z}
$$

where $\xi_{i}$ is a basic scalar meteorological variable (e.g., T, $u$, or $v)$ at the $i^{\text {th }}$ level, $\Delta z$ is the distance between observations (e.g., $\Delta z=25 \mathrm{~m}$ for $\mathrm{J} / \mathrm{J}$ and $250 \mathrm{~m}$ for the $\mathrm{RW}$ data set) and $\mathrm{N}$ 
TABLE I

Cape Kennedy Conjunctive Rawinsonde (RW)

Jimsphere/Jimsonde (J/J) Data Summary

$$
\begin{aligned}
\mathrm{RW}: & \mathrm{U}, \phi, \mathrm{T} ; \Delta \mathrm{z}=250 \mathrm{~m} \\
\mathrm{~J} / \mathrm{J}: & \mathrm{U}, \phi, \mathrm{T}, \dot{\mathrm{z}} ; \Delta \mathrm{z}=25 \mathrm{~m}
\end{aligned}
$$

Approximately 90 flights from summer 1970 through summer 1972. Altitude range: about $1-18 \mathrm{Km}$.

$$
\begin{aligned}
U & =\text { Horizontal Wind Amplitude } \\
\phi & =\text { Horizontal Wind Direction } \\
\mathrm{T} & =\text { Temperature } \\
\dot{\mathbf{z}} & =\mathrm{J} / \mathrm{J} \text { Rise Rate } \\
\Delta \mathbf{z} & =\text { Height Interval between observations }
\end{aligned}
$$


is the number of grid points in the specified interval of calculation, $\Delta h$, such that

$$
\Delta \mathrm{h}=(\mathrm{N}-\mathrm{I}) \Delta \mathrm{z}
$$

The vector vertical shear amplitude of the horizontal wind is

$$
|\Lambda|=\left[(d u / d z)^{2}+(d v / d z)^{2}\right]^{1 / 2}
$$

with

$$
\Lambda \equiv d v / d z=(d u / d z) \ddot{i}+(d v / d z) \ddot{p} .
$$

The Brunt-Väisälä frequency, a measure of the degree of atmospheric static stability, is defined by

$$
N_{B}^{2} \equiv g / T(\Gamma-\gamma)
$$

where

$$
\begin{array}{ll}
\gamma \equiv \mathrm{dT} / \mathrm{dz} & \text { : vertical temperature gradient, } \\
\Gamma \equiv \mathrm{g} / \mathrm{c}_{\mathrm{p}} & \text { : adiabatic lapse rate, } \\
\mathrm{c}_{\mathrm{p}} & \text { : specific heat at constant pressure, } \\
\mathrm{g} & \text { : gravity, and } \\
\overline{\mathrm{T}} & \text { : mean temperature through interval } \Delta \mathrm{h} .
\end{array}
$$

The choice of the interval of calculation, $\Delta h$, is of considerable importance. The optimum interval should be small enough to resolve mesoscale shear layers yet not so small as to mask these shear layers while producing unreliably noisy results. A computation scheme which used a variable interval of calculation might be ideal. For this study, however, such an approach was deemed impractical. The interval of calculation was chosen to be $\Delta h=500 \mathrm{~m}$ so that the resolution of the Rawinsonde data was maximized, as well, this value seems to be of an appropriate scale to resolve most important mesoscale shear layers. 
SECTION 2

THE CAT PRODUCING MECHANISM

It is well established that significant CAT events are almost exclusively associated with statically stable layers possessing strong vertical shears. A measure of conditions thought necessary for the existence of clear air turbulence that developed early in investigations of atmospheric turbulence was the Richardson number defined as

$$
\mathrm{Ri} \equiv \mathrm{N}_{\mathrm{B}}^{2} /|\Lambda|^{2}
$$

In general, when $\mathrm{Ri}$ falls below some critical value, $\mathrm{Ri}_{C}$ ' turbulent conditions may ensue. It was found (e.g.. Miles, 1961; Howard, 1961) that $\mathrm{Ri}_{\mathrm{C}}$ needed to be considerably less than one. Since statically stable layers are characterized by large $\mathrm{N}_{\mathrm{B}}{ }^{2}$, an especially large shear is necessary in order that $R i$ be sufficiently small. The general tendency for larger shear to be associated with large static stability is illustrated in Figure 1 . Shown is the correlation diagram for the Brunt-väisälä frequency squared (a measure of static stability) and the vector shear at equal levels as calculated from $\mathrm{J} / \mathrm{J}$ flights. The shading roughly indicates the frequency of nearly equal observations: $\operatorname{dots}=1-5$; hatched $=6-16$; and solid $=17$ and greater. The correlation coefficient, $r$, is 0.412 . Thus, synoptic scale patterns which can produce areas of strong shear in statically stable layers (i.e., small Ri) may be highly correlated to CAT events.

The vertical variation of $\mathrm{Ri}$ as calculated from the $\mathrm{J} / \mathrm{J}$ flight data for 16 October 1970 at $1345 \mathrm{z}^{*}$ is illustrated in Figure 2. Several layers of relatively small Ri can be noted. Figure 3 also shows that several layers possessing small Ri, especially near $10 \mathrm{Km}$, existed on 18 February 1971 at $1445 \mathrm{z}$ over Cape Kennedy. The vertical broken line delineates Ri=1.

\footnotetext{
*The nomenclature $1345 \mathrm{z}$ is equivalent to 1345 GMT (Greenwich Mean Time).
} 


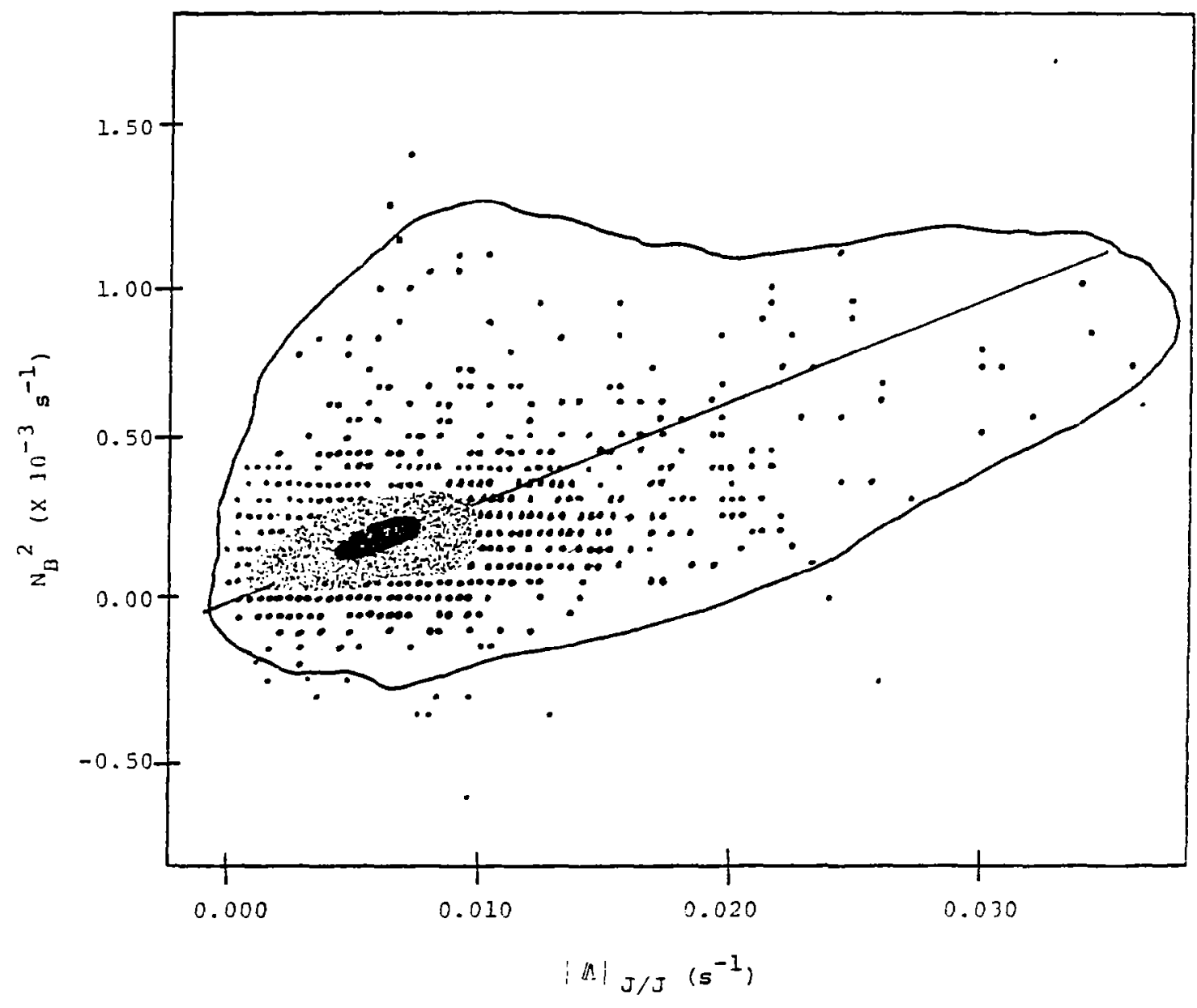

Figure 1. Correlation diagram showing the Brunt-Väisälä frequency squared versus the vector shear amplitude of the horizontal wind. 


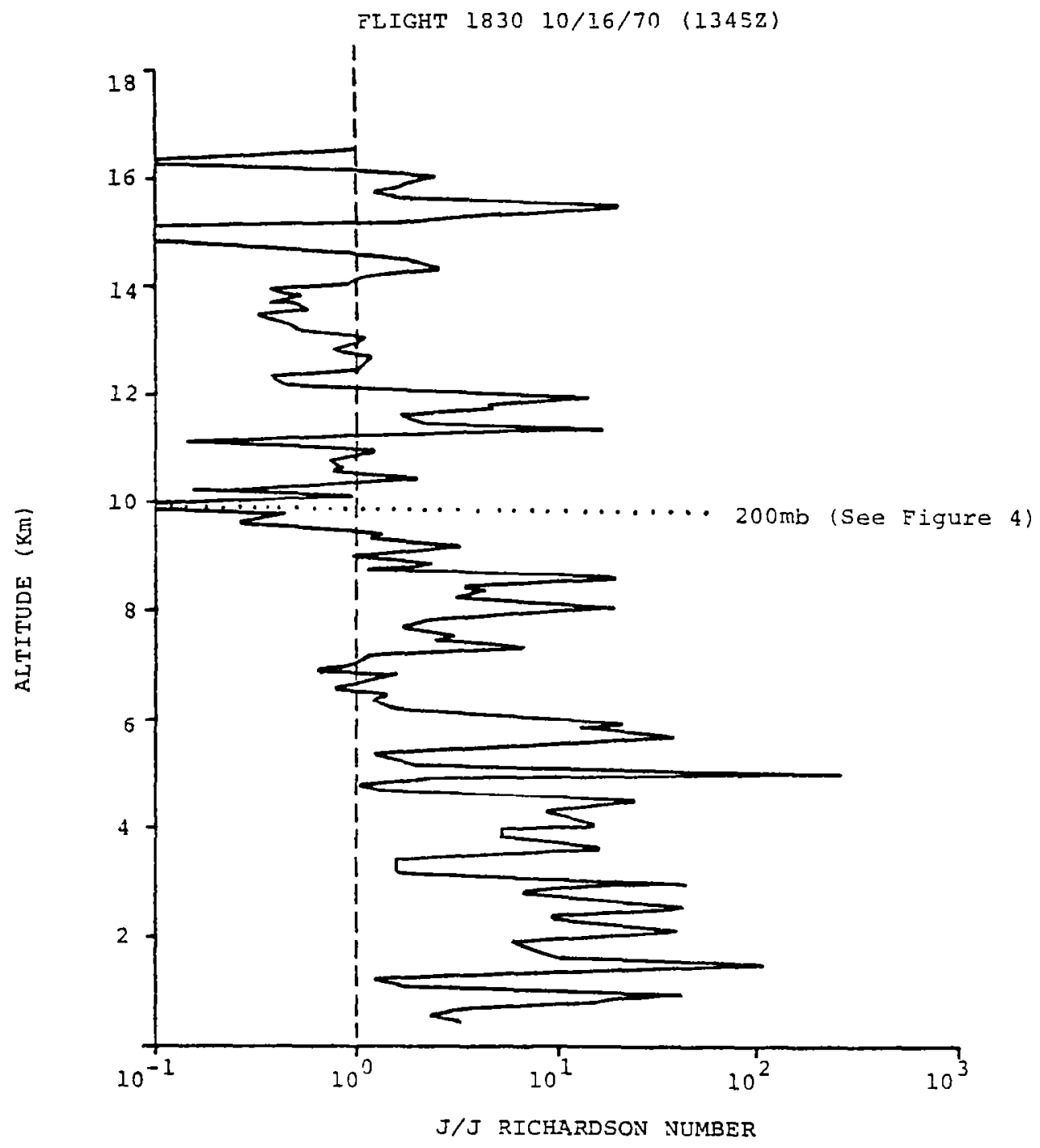

Figure 2. Vertical profile of the Ri number as calculated from the data obtained from the J/J flights of 1345216 October 1970 . 
FLIGHT $49502 / 18 / 71 \quad(1445 Z)$

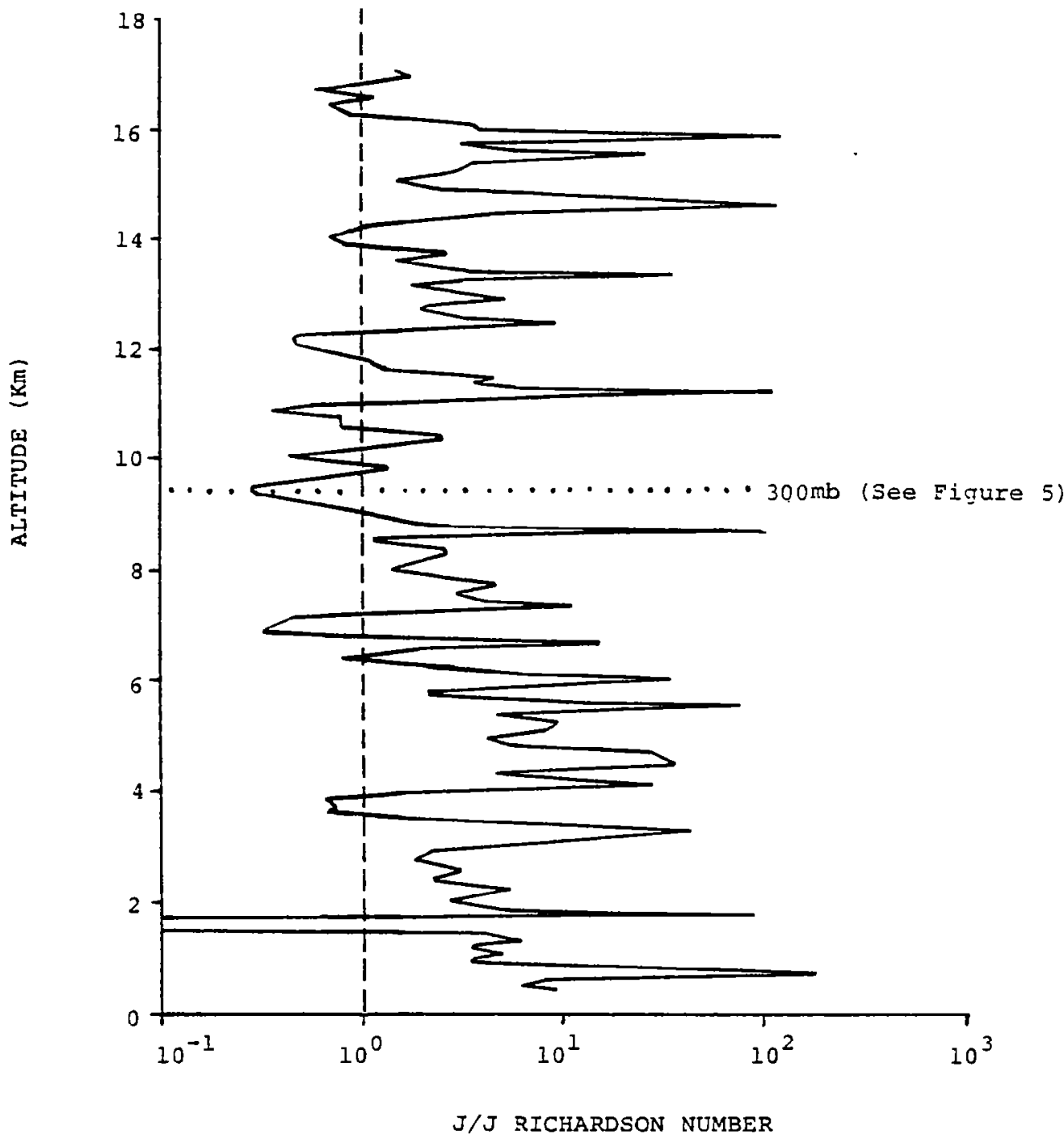

Figure 3. Vertical profile of the $\mathrm{Ri}$ as calculated from the data obtained from the J/J flight of $1445 \mathrm{Z} 18$ February 1971. 
The interval of calculation was $\Delta \mathrm{h}=500 \mathrm{~m}$ and the plots show sliding fit values every 25m. Figures 4 and 5 show, respectively, the $200 \mathrm{mb}$ * constant pressure level chart for $1200 \mathrm{z} 16$ October 1970 and the $300 \mathrm{mb}$ constant pressure level chart for $1200 \mathrm{z}$ 18 February 1971. These charts show the synoptic scale patterns which existed in the Southeastern United States at these respective $\mathrm{J} / \mathrm{J}$ flight times at the level of smallest Richardson numbers. Inspection reveals that the synoptic patterns were quite different. The conclusion must be that there exists no single synoptic scale pattern which uniquely provides the condition necessary for the existence of turbulence.

Further inspection of these synoptic conditions reveals that the small Richardson numbers detected by the $\mathrm{J} / \mathrm{J}$ flight of 16 October 1970 were apparently due to strong vertical shear produced by a thermal wind response to the horizontal temperature field in a statically stable layer associated with an upper level frontal zone. The situation of 18 February 1971 appears to be an example of vertical shear produced by the subtropical jet stream in predominantly gradient wind balance due to the strong anticyclonic curvature. This same curvature can be associated with subsidence-produced statically stable layers. Within such a layer may exist mesoscale inhomogeneities in the static stability.

At this point it appears that an effort must be made to clarify the distinction between turbulence in general and the mechanism responsible for CAT in particular. There have been numerous observational studies of the structure of CAT using various turbulence detectors (e.g., Atlas, et al., 1970; Boucher, 1970, 1973; Hicks, 1969; Reed and Hardy, 1972). These studies revealed a structure which was highly suggestive of breaking unstable Kelvin-Helmholtz $(\mathrm{K}-\mathrm{H})$ waves. As a result, the earlier theoretical research on $\mathrm{K}-\mathrm{H}$ instability provided the groundwork for later laboratory, numerical, and theoretical investigations into the CAT mechanism (e.g... Stoeffler and

\footnotetext{
${ }^{\star}$ i.e., 200 millibar.
} 


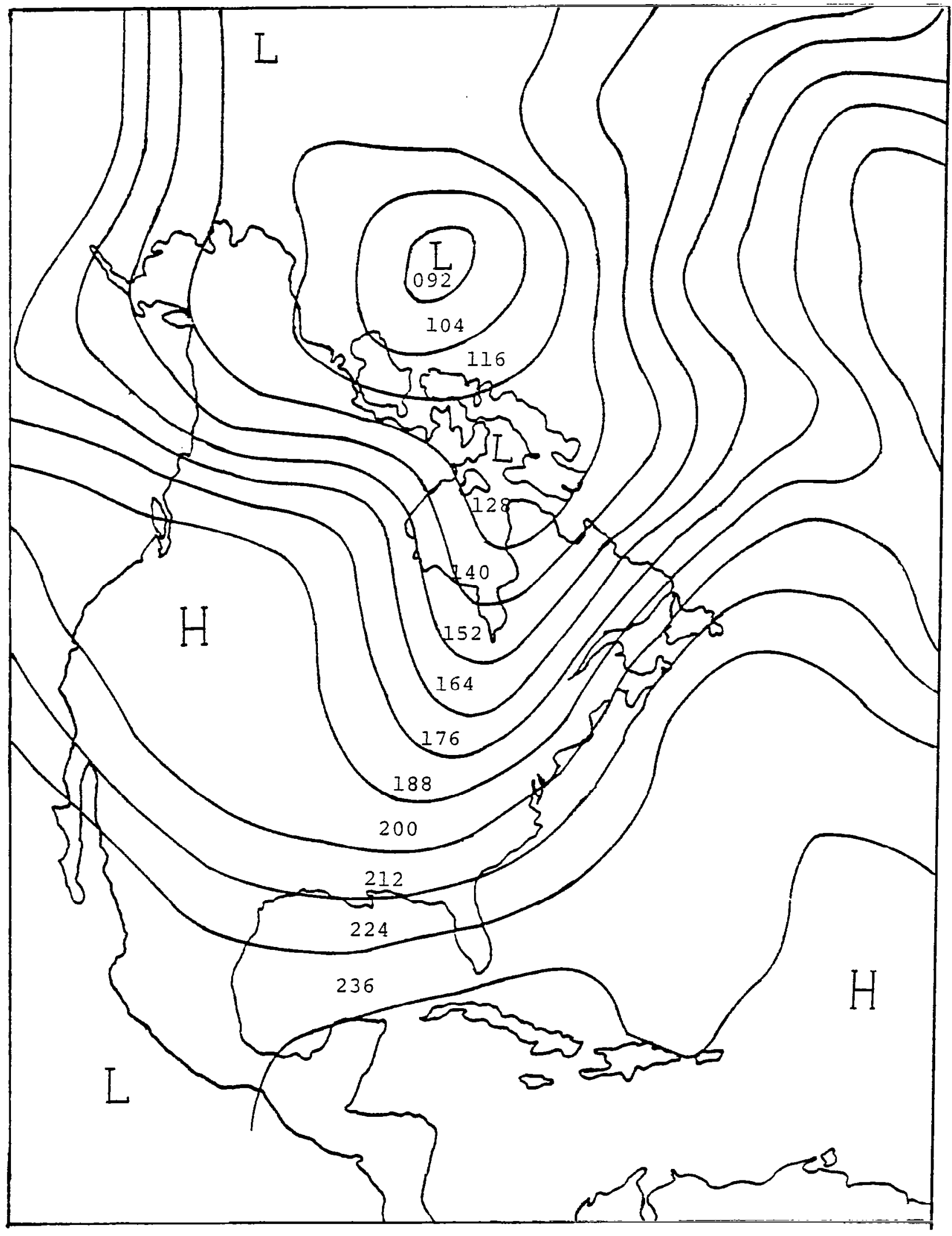

Figure 4. The 200mb constant pressure level chart for $1200 \mathrm{z}$ 16 October 1970. Shown are lines of constant height in decameters ( $10^{1}$ meters) minus $10 \mathrm{Km}$; for example, $1.88=11880$ meters. 


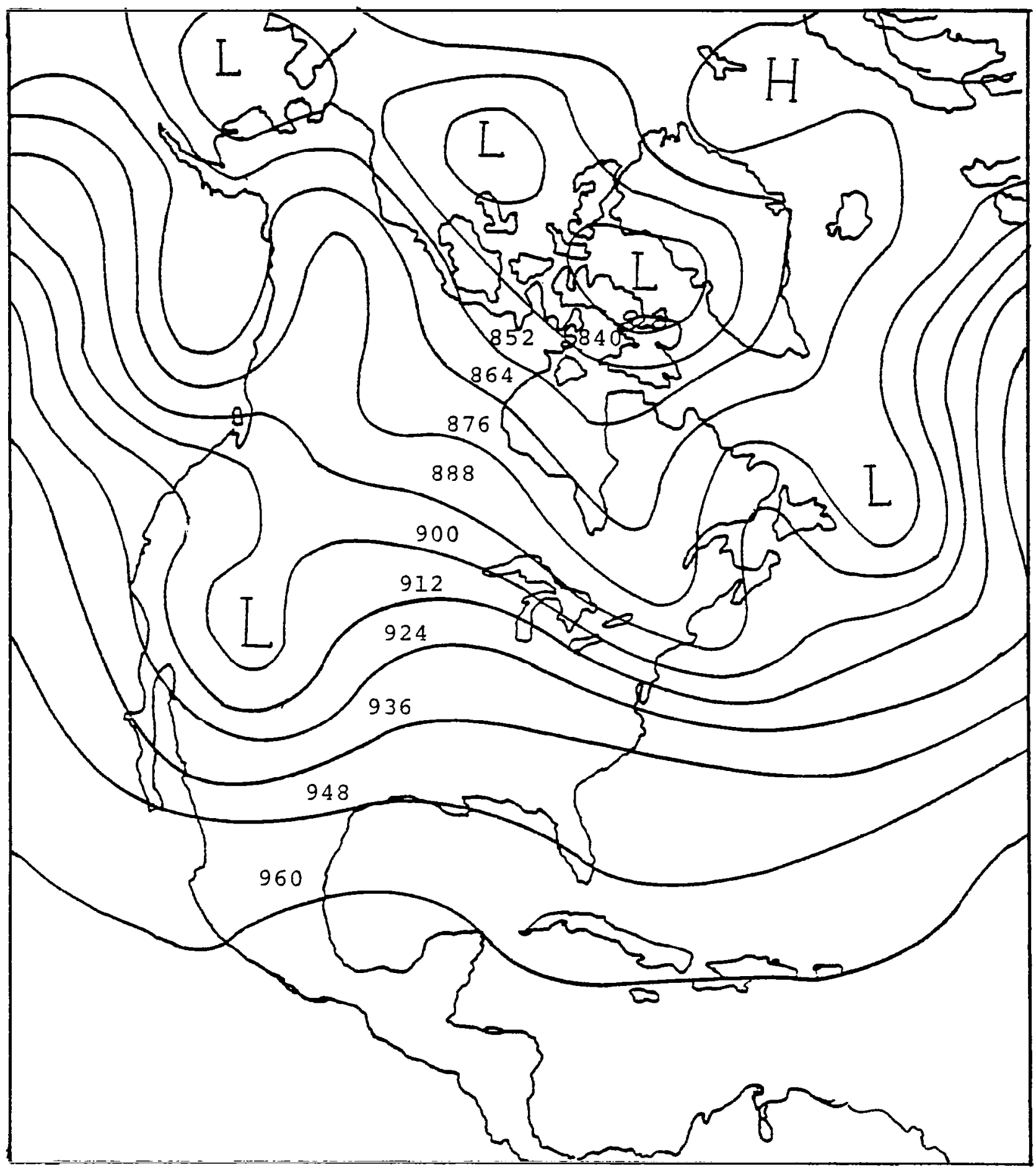

Figure 5. The $300 \mathrm{mb}$ constant pressure level chart for $1200 \mathrm{z}$ 18 February 1971. Shown are lines of constant height in decameters (101 meters). 
Clark, 1970; Atlas and Metcalf, 1970; Kogan, 1973; Lindzen, 1974). This has culminated in recent years in a realistic and physically consistent model of the CAT mechanism in terms of shearlayer normal mode instabilities in the presence of a solid lower boundary (e.g., Lalas, et al., 1976; Lindzen and Rosenthal, 1976; Acheson, 1976). This model deals essentially with the energetics of unstable $\mathrm{K}-\mathrm{H}$ type gravity waves associated with a Helmholtz velocity profile. The dynamics and energetics of the turbulent scale motions are not explicitly considered.

The Helmholtz velocity profile (Figure 6) approximates a shear layer (through a finite depth) with a velocity discontinuity at $z=0$. Thus, a vector shear amplitude of $0.020 \mathrm{~s}^{-1}$ calculated through $\Delta \mathrm{h}=500 \mathrm{~m}$ is assumed equivalent to a $20 \mathrm{~m} \cdot \mathrm{s}^{-1}$ Helmholtz velocity jump. The vertical coordinate is centered $(z=0)$ at a distance $H$ above the surface so that the earth's surface is $-\mathrm{H}$ below the shear layer.

A given statically stable shear layer may, under the right conditions, generate unstable $\mathrm{K}-\mathrm{H}$ type gravity waves. These waves will then amplify until, due to the existence of vertical wind shear, they "break" forming a vortex sheet. The resulting energy cascade is responsible for the formation of "quasiisotropic" turbulence embedded within the shear layer. If the time scale of adjustment to an equilibrium state is rapid relative to the slowly varying synoptic scale wind and temperature field to which the CAT mechanism (a mesoscale phenomenon) owes its existence, a steady state may be considered to have been obtained. As long as the dynamics are such that the synoptic scale motion field continues to attempt to "violate" the balance between shear and static stability, the CAT layer is maintained. In this way a CAT layer acts as an internal energy sink for the large scale motion field. Figure 7 shows a schematic diagram of the CAT mechanism which apparently operates to produce turbulent conditions within statically stable shear layers in the free atmosphere. 


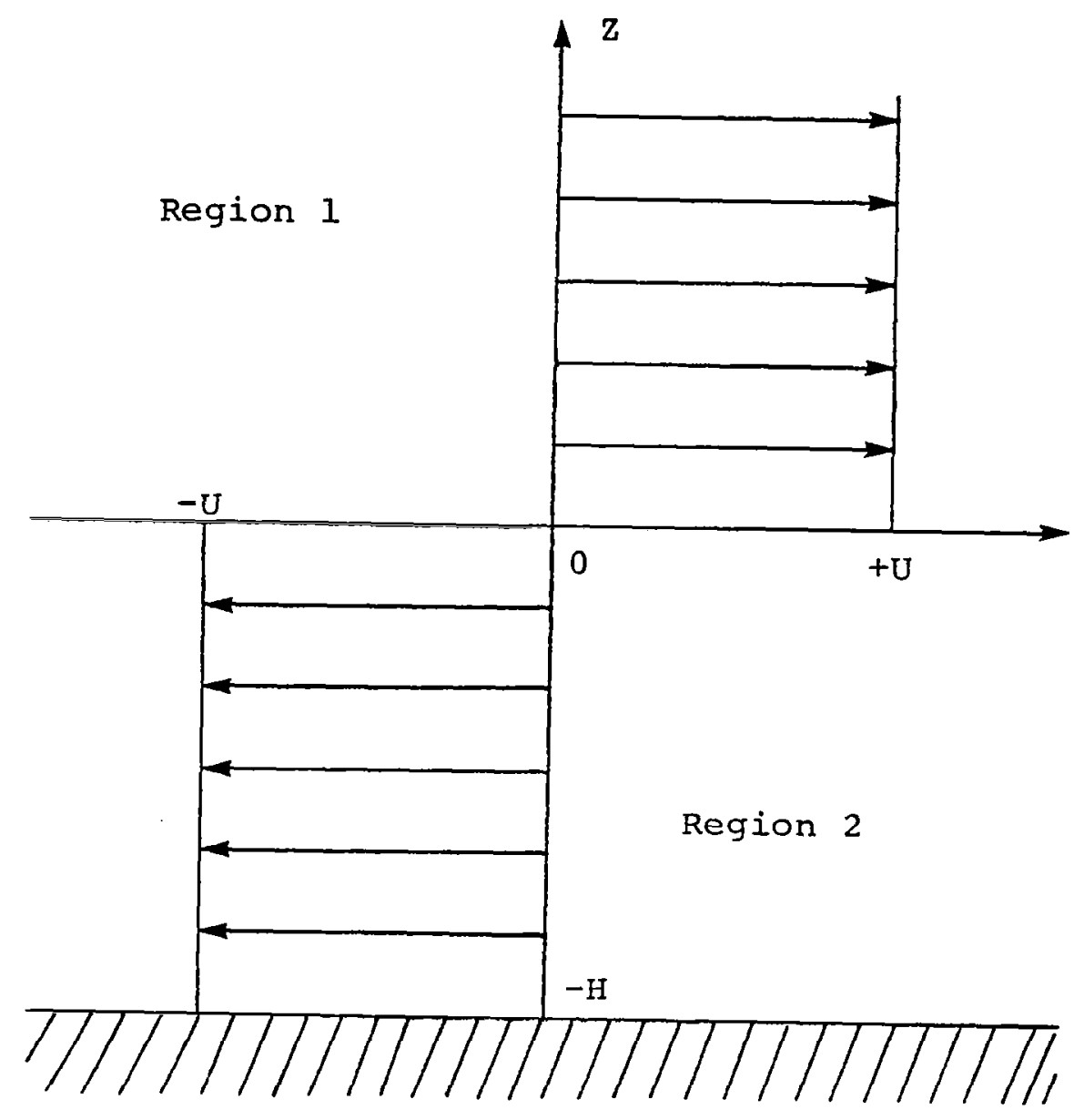

Figure 6. The Helmholtz mean velocity profile. 


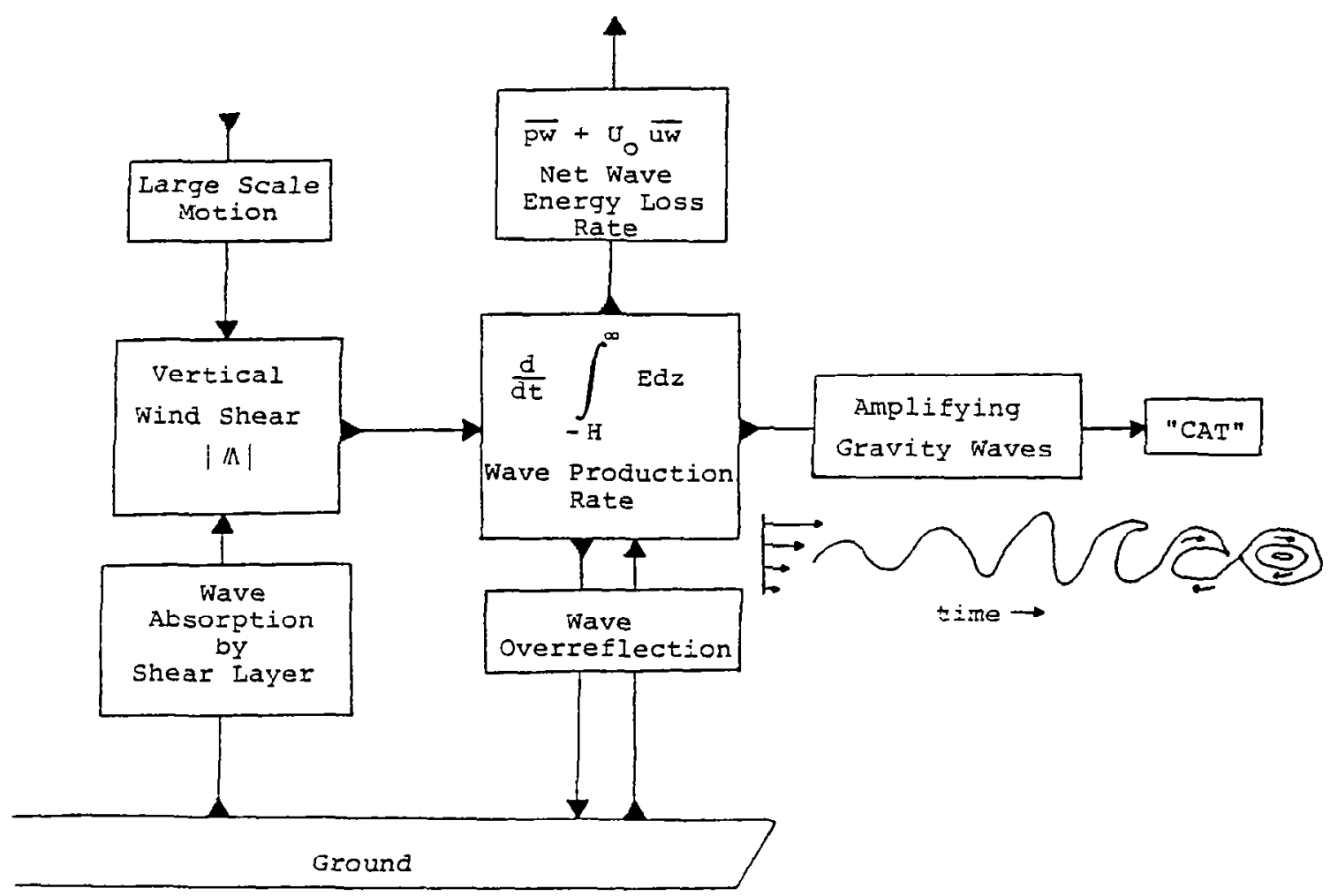

Figure 7. The CAT mechanism. 
The instability appears to be due to over reflection in the presence of a lower boundary (e.g., Acheson, 1976). The intensity of the CAT will depend upon the amplitude of the $\mathrm{K}-\mathrm{H}$ wave instability (e.g., Atlas and Metcalf, 1970). The amplitude attained by such an amplifying wave is dependent upon the wave production rate (or amplification efficiency),

$$
\frac{d}{d t} \int_{-H}^{\infty} E d z \text {, }
$$

where

$$
\begin{aligned}
& E=1 / 2 \rho_{s}\left[u^{\prime 2}+w^{\prime 2}+\left(g / N_{B}\right)^{2}\left(\rho^{\prime} / \rho_{s}\right)^{2}\right]: \text { perturbation energy } \\
& \mathrm{H} \quad \text { : height of the shear layer, } \\
& \text { Ps : basic state density, } \\
& \rho^{\prime} \quad \text { : perturbation density, and } \\
& u^{\prime}, w^{\prime} \quad \text { : perturbation eastward and vertical wind } \\
& \text { component }
\end{aligned}
$$

minus the net rate of wave energy being propagated away:

$$
{\overline{\mathrm{p}^{\prime} \mathrm{w}^{\prime}}}^{\prime} \mathrm{U}_{\mathrm{O}} \overline{\mathrm{u}^{\prime} \mathrm{w}^{\prime}}
$$

where

$$
\begin{aligned}
& \mathrm{p}^{\prime} \quad \text { : perturbation pressure, and } \\
& \mathrm{U}_{\mathrm{O}} \text { : mean wind amplitude }
\end{aligned}
$$

and the overbar indicates average over a wavelength.

The resulting wave production rate within the shear layer depends upon the height of the shear layer $H$, and its characteristic Brunt-väisälä frequency, $N_{B}$, and vector shear $|M|$. The magnitude of these parameters are largely a result of the synoptic motion field but lower tropospheric gravity-wave sources (i.e., mountainous terrain, thunderstorms) probably provide an additional source of momentum to atmospheric shear layers via critical layer interactions (e.g., Hines, 1968; Bretherton, 1969; Jordan, $1972)$. 
The results of applications of this $\mathrm{K}-\mathrm{H}$ gravity wave model are in favorable qualitative and quantitative agreement with observations of unstable shear layers and numerical investigations of turbulent scale motions. Figure 8, taken from Vinnichenko and Dutton (1969), shows average spectra of the horizontal wind components in the free atmosphere obtained from numerous aircraft flights. A slope of $-5 / 3$ is characteristic of scales of motion from the lower end of the mesoscale through the turbulent subrange. The lines " $a$ " and "b" designate typical spectra obtained for severely turbulent and tranquil conditions respectively. Evidence that spectra of this nature are a manifestation of a breaking $\mathrm{K}-\mathrm{H}$ type unstable gravity wave is provided by the results obtained from numerical modeling of these waves. Figure 9, taken from Reiter (1969), illustrates an example of a spectrum of a modeled breaking $\mathrm{K}-\mathrm{H}$ wave. The lefthand side shows the amplification and "breaking" of the waveform function (approximated by advancing the maximum through time) and the right-hand side the power spectrum of the wave delineated by the heavy line. The Fourier decomposition of the wave shows that the energy is distributed among the wave components in such a way that the spectral slope is approximately $-5 / 3$. Despite the simplifications involved, these results lend substantial quantitative evidence supporting the role of breaking $\mathrm{K}-\mathrm{H}$ waves to empirical evidence as obtained by sensitive radars.

The CAT producing mechanism outlined above provides an accurate model which can be used in considerations of the turbulence sensing capabilities of rising spheres. The turbulent and mesoscale components of motion are coupled so that the ability to sense the latter may give considerable information about the former. 


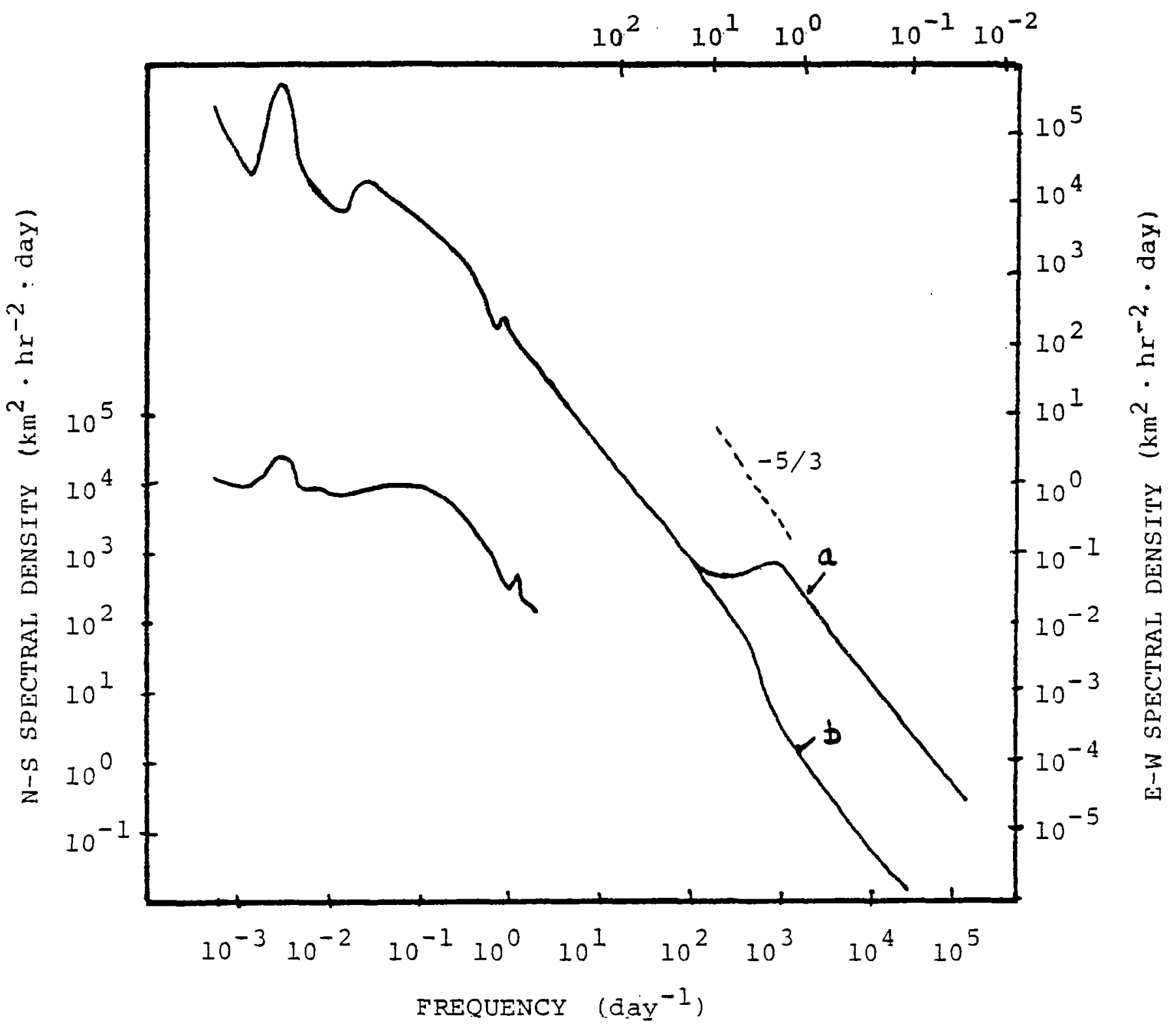

Figure 8. Average spectra of the horizontal wind components in the free atmosphere obtained from numerous aircraft flights; sketched from Vinnichenko and Dutton (1969). 

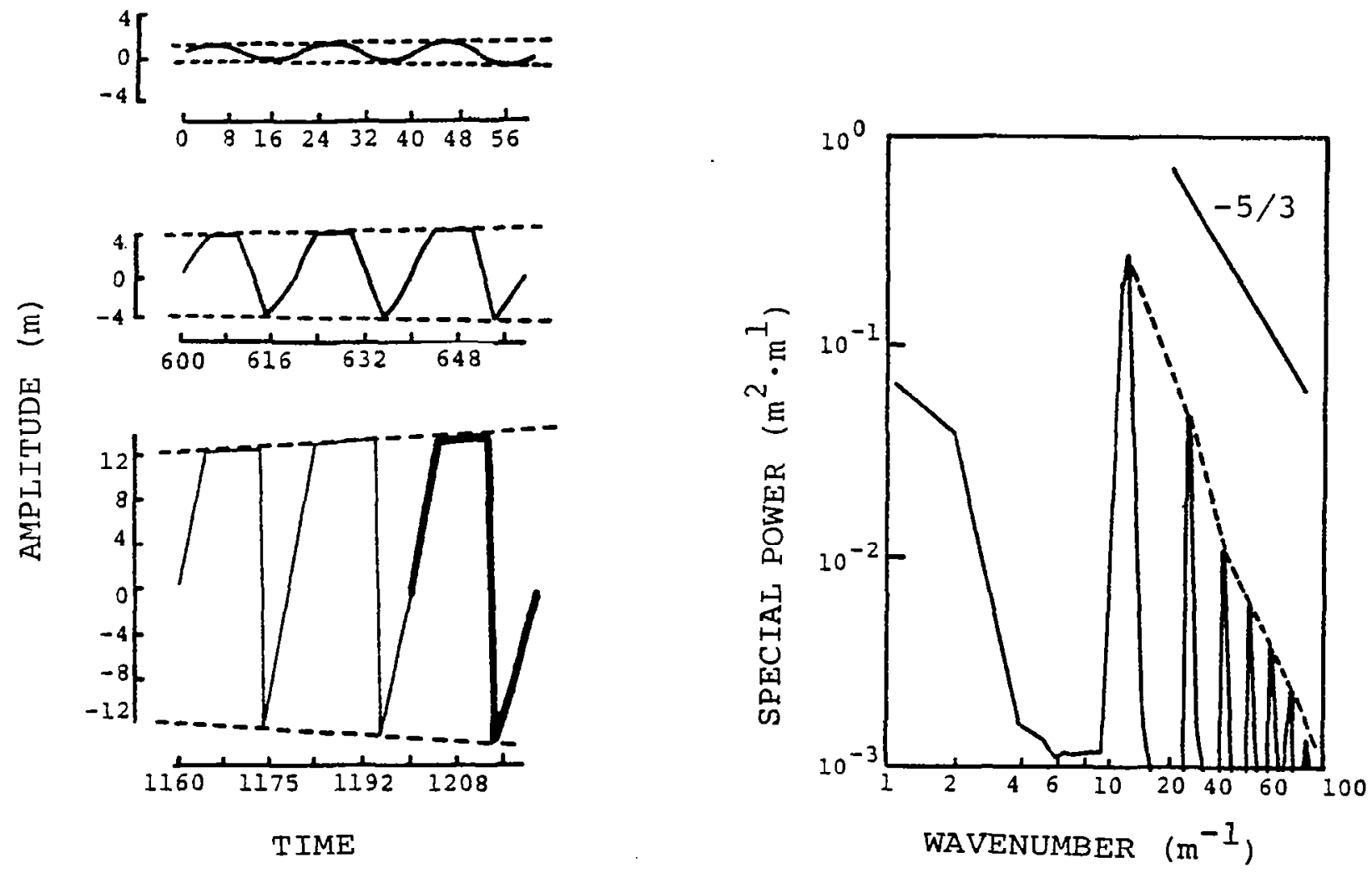

Figure 9. An example of a spectrum of a modeled breaking $\mathrm{K}-\mathrm{H}$ wave sketched from Reiter (1969). 


\section{SECTION 3}

THE RAWINSONDE AS A TURBULENCE SENSOR INFORMATION FROM VERTICAL WIND PROFILES

\subsection{DIRECT SENSING OF TURBULENCE}

The first question addressed was: Can the J/J system act as a direct sensor of turbulent scale motions? In light of objective interpretation of statistical results and subjective consideration of the CAT mechanism, the answer seems to be "no". If the $\mathrm{J} / \mathrm{J}$ system cannot clearly sense these motions then the RW system can hardly be expected to do so. Such an ability is dependent upon the sensitivity of the balloon system to turbulent motions above the noise (error) of the system and the vertical resolution. Possible sources of system error include (e.g., Scoggins and Armendariz, 1969): 1) errors in tracking; 2) selfinduced balloon motions; and 3 ) imperfect balloon response. These system errors lead to root mean square wind errors of about $0.5 \mathrm{~m} \cdot \mathrm{s}^{-1}$ for winds calculated over a 25 meter layer. For the horizontal wind speed this represents a small fraction of the average wind amplitude. However, this is of the same order of magnitude of vertical velocities obtained from $\mathrm{J} / \mathrm{J}$ rise rates calculated over a 25 meter layer. If the vertical rise rate is filtered (e.g., Demandel and Krivo, 1968), the error is reduced by an order of magnitude. Since the $\mathrm{J} / \mathrm{J}$ system employs a more sensitive radar (FPS-16) and yields the highest resolution data, this system was analyzed for its ability to reliably detect turbulent scale motions.

If the $\mathrm{J} / \mathrm{J}$ system can detect the turbulent motions (less than $100 \mathrm{~m}$ ) it should be manifested in increased variance in the wind components in regions of the atmosphere possessing statically stable shear layers, that is, well correlated to small Richardson numbers. Figure 10 shows the correlation diagram relating the dispersion of the vertical wind (i.e., standard deviation of the vertical wind calculated from the filtered $\mathrm{J} / \mathrm{J}$ rise rates, $\sigma_{w}$ ) to the Ri. The correlation coefficient is -0.087 . Thus, the 


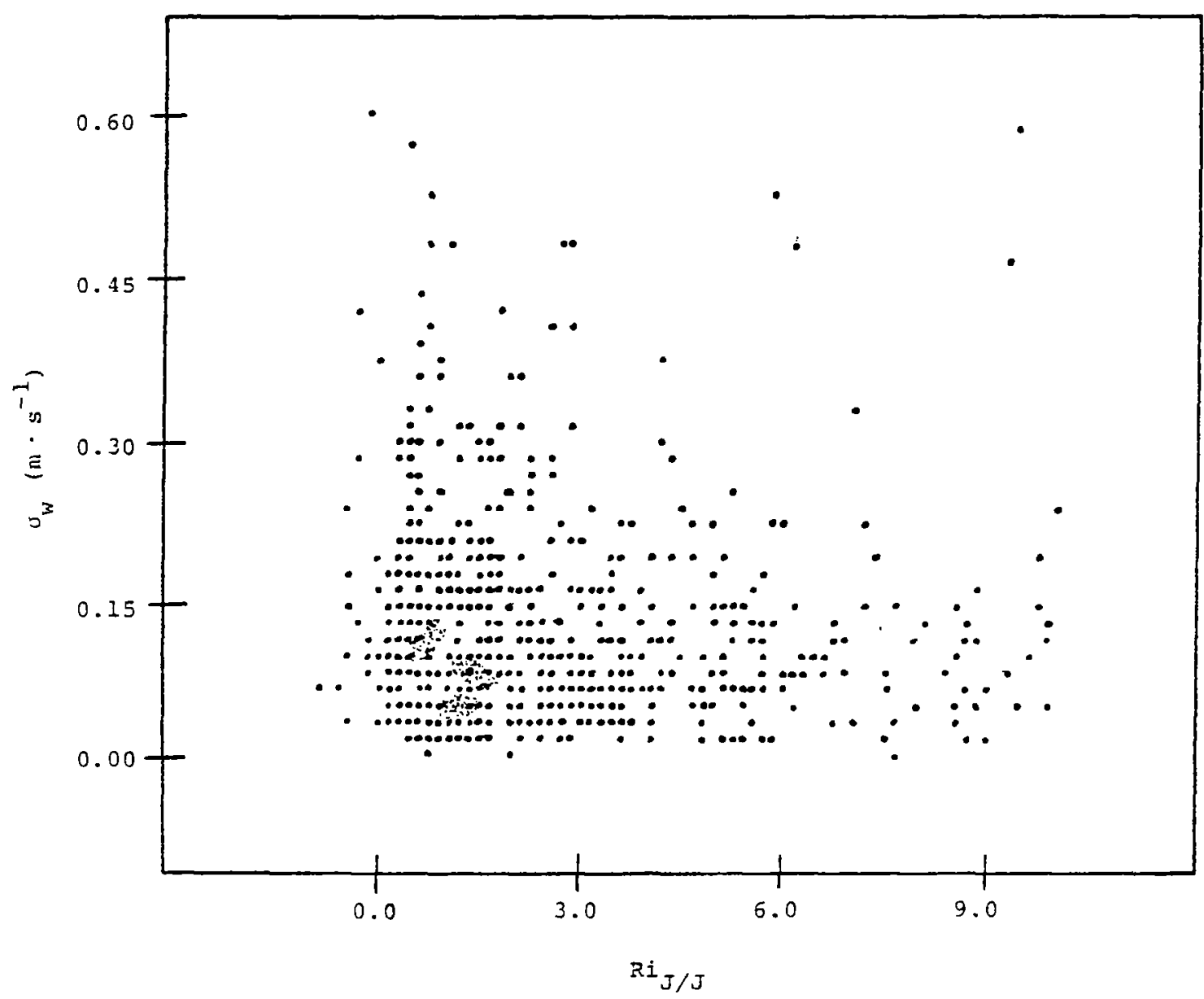

Figure 10. The correlation diagram relating the standard deviation of the vertical wind calculated from the filtered $\mathrm{J} / \mathrm{J}$ rise rates, $\sigma_{\mathrm{W}}$, to the $\mathrm{R} i$. 
vertical velocity variation is not reliably correlated to this parameter such that turbulent layers can be unambiguously identified. The J/J system has been shown to be highly sensitive to horizontal motions even at turbulent scales (Luers and MacArthur, 1972). However, inspection of Figure 11 shows a relatively smooth variance of the horizontal wind amplitude through the very strong shear layer located near $10 \mathrm{~km}$. It might be expected that the turbulent component of the horizontal wind would be apparent, if anywhere, as "noise" or perturbations through such a strong shear layer. However, if the nature of the CAT mechanism is considered, the relative "smoothness" of the horizontal wind profile seems less surprising. That is, since the breaking waves and embedded turbulence in a CAT layer tend to propagate at nearly the same speed as the mean wind at the level of wave production (Lindzen and Rosenthal, 1976; Acheson, 1976), the balloon would merely "ride along" with the unstable gravity wave without detecting any significant perturbations. On the other hand, a jet-liner would have a very large speed relative to the breaking wave and hence would feel the turbulent wind component as a disconcertingly bumpy ride.

\subsection{INDIRECT SENSING OF TURBULENCE}

Failing at direct probing of atmospheric turbulence, the possibility of indirect sensing must be considered. Such an approach involves the evaluation of the relative capabilities of the $\mathrm{J} / \mathrm{J}$ and $\mathrm{RW}$ systems to accurately resolve mesoscale turbulent layers associated with CAT. Initially, discussion will focus on the Richardson number as it relates to turbulent conditions. The discussion will then be directed towards the basic components which comprise the Richardson number - the atmospheric static stability and especially the vector shear amplitude.

\section{3 RICHARDSON NUMBER}

Figures 12 and 13 show, respectively, the vertical profiles of the Ri as calculated from the RW system (16 October 1970 


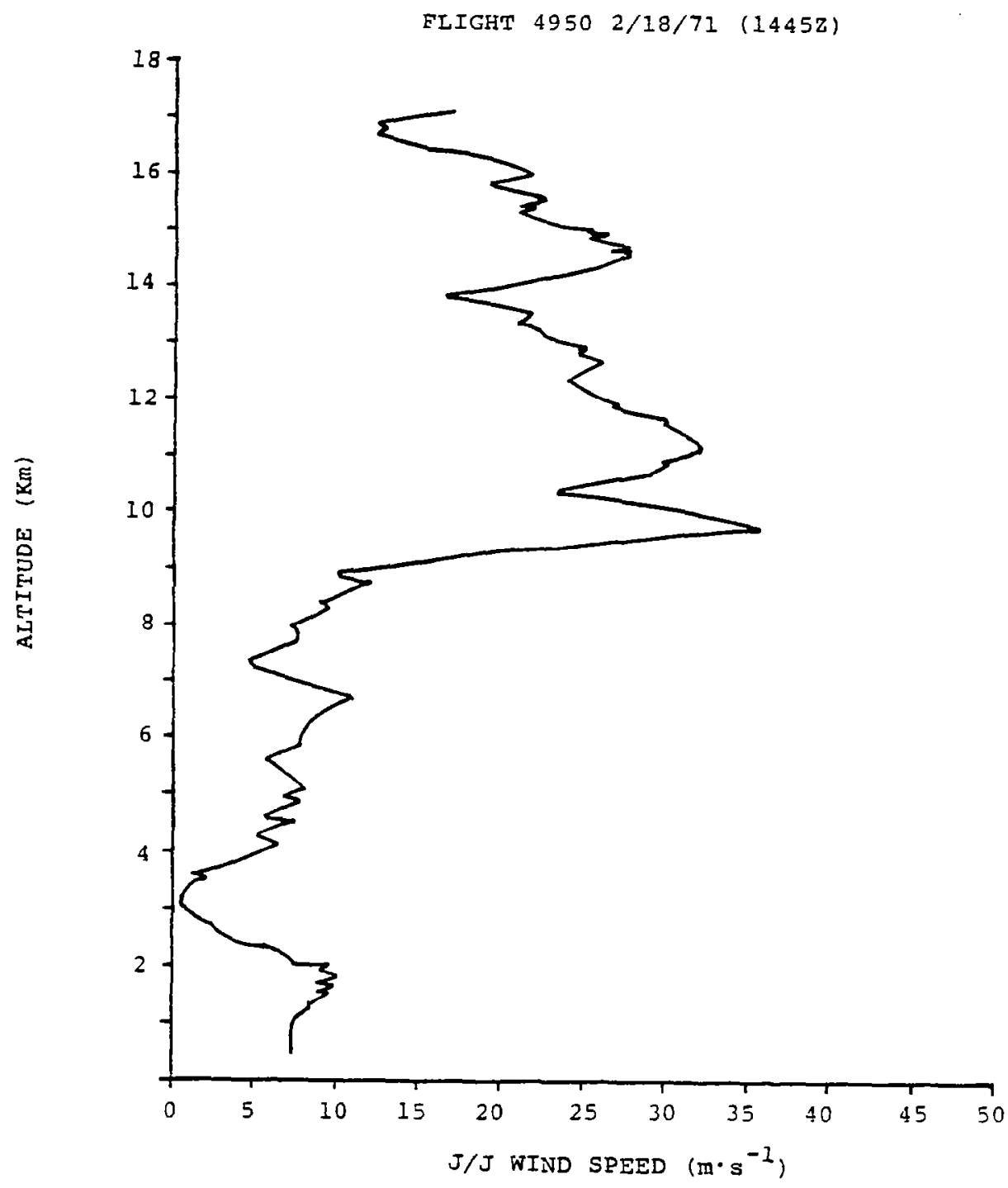

Figure 11. The height variation of the horizontal wind measured by the $\mathrm{J} / \mathrm{J}$ system for $1445 \mathrm{Z}$ 18 February 1971 . 


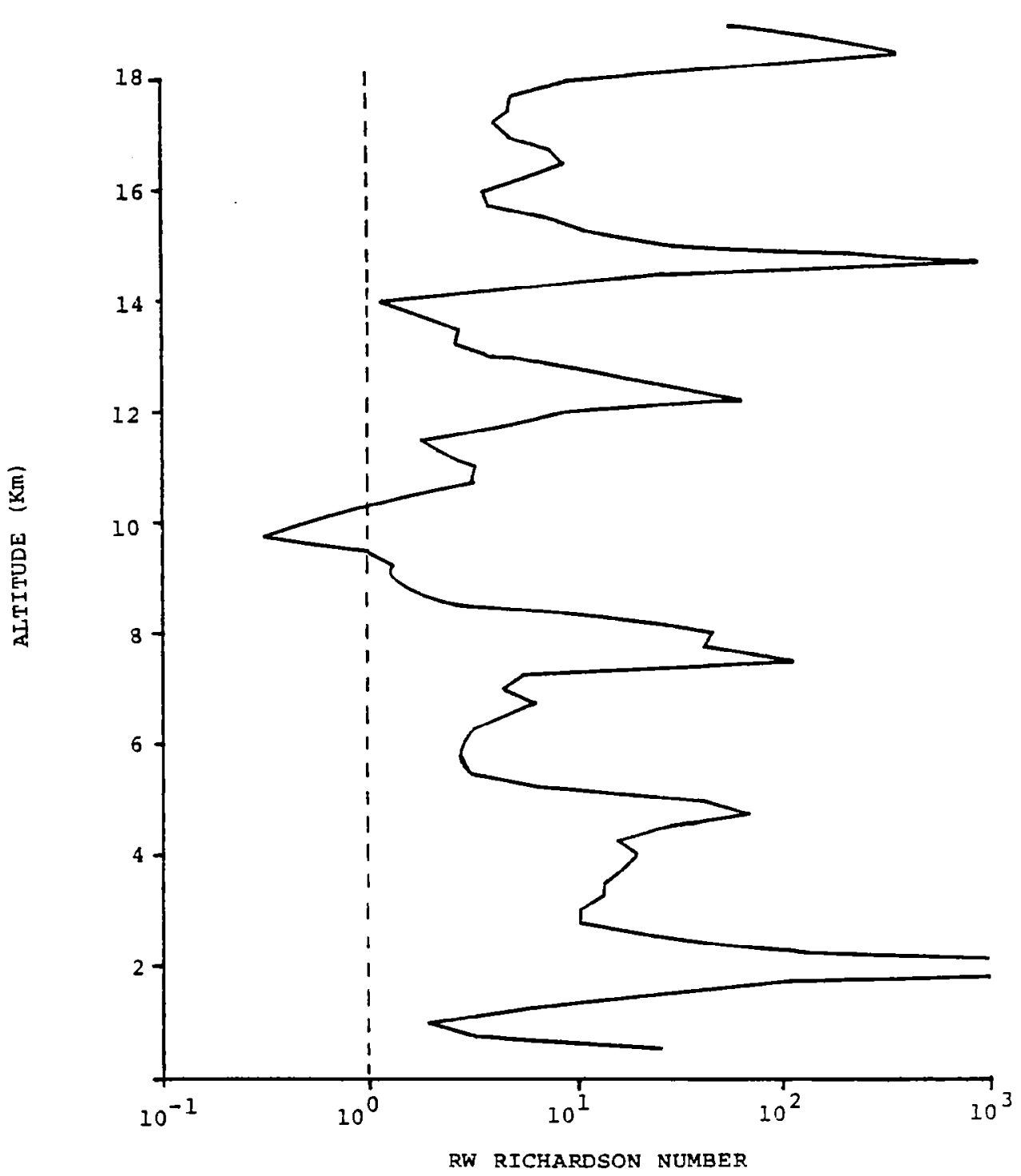

Figure 12. Vertical variation of the $\mathrm{Ri}$ as calculated for the RW flight of $1015 \mathrm{z} 16$ October 1970. 
FIIGHT $49502 / 18 / 71$ (11202)

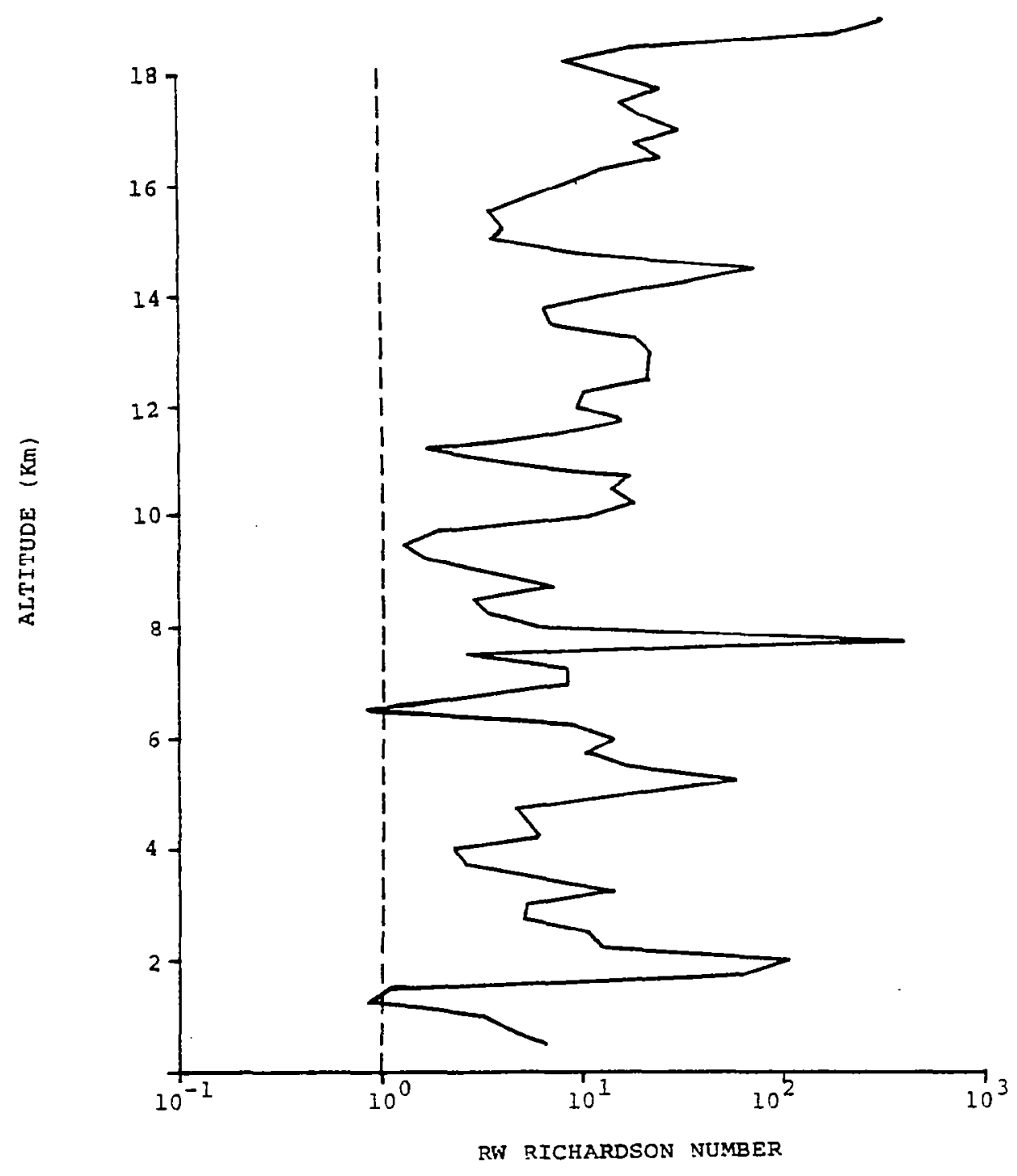

Figure 13. Vertical variation of $\mathrm{Ri}$ as calculated for RW flight of 1120218 February 1971. 
and 18 February 1971). The interval of calculation was $\Delta \mathrm{h}=500 \mathrm{~m}$ and the plots are sliding fit values calculated every $250 \mathrm{~m}$. These can be compared with Figure 3 and 4 for which concurrent higher resolution $\mathrm{J} / \mathrm{J}$ vertical data was used. It can be seen that, in general, the Ri calculated form the RW data tend to be larger than those calculated using the $\mathrm{J} / \mathrm{J}$ data. Such an observation results from the finer scale resolution ( $\Delta z=25 \mathrm{~m}$ ) available with the $\mathrm{J} / \mathrm{J}$ sensor and is consistent with the general conclusions of certain previous studies (e.g., Reiter and Lester, 1968). Figure 12 shows a relative minimum of $\mathrm{Ri}$ corresponding to that in Figure 3. The same features can be noted near 7 and $10 \mathrm{Km}$ in Figare 13. Thus, the following question may be asked: Is there a general, consistent relationship between the RW and J/J Ri's such that the former can be adjusted (or weighted) to account for its decreased resolution? Although these examples indicate a qualitative correlation, in general, the answer appears to be decisively negative.

Figure 14 shows the correlation diagram at equal levels for $\mathrm{Ri}_{\mathrm{RW}}$ and $\mathrm{Ri} J / \mathrm{J}$ for the range of Richardson number $-1<\mathrm{Ri}<10$. The correlation is both qualitatively and quantitatively poor $(r=0.101)$. The $\mathrm{J} / \mathrm{J}$ system relative to the $\mathrm{RW}$ system is both more sensitive and accurate. The results can then be analyzed by assuming the $\mathrm{J} / \mathrm{J}$ is the more accurate sensor. The $\mathrm{J} / \mathrm{J}$ detected 244 layers for which $\mathrm{Ri}<1$ of which the RW was in agreement with 39 . Another 33 cases of $\mathrm{Ri}<I$ were apparently erroneously detected by the RW system for a total of 72 . In essence, the result is an RW sensitivity of $39 / 244(0.16)$ with a corresponding RW error of $33 / 72(0.46)$. Thus, no clear and reliable relationship exists between the two Ri's. Figure 15 shows graphically the general dependence of the error in the $\mathrm{Ri}$ upon the resolution used in calculating the wind shear and vertical temperature gradient. This ratio is shown for three cases: case A corresponds to moderate static stability and weak shear; case $B$, moderate 


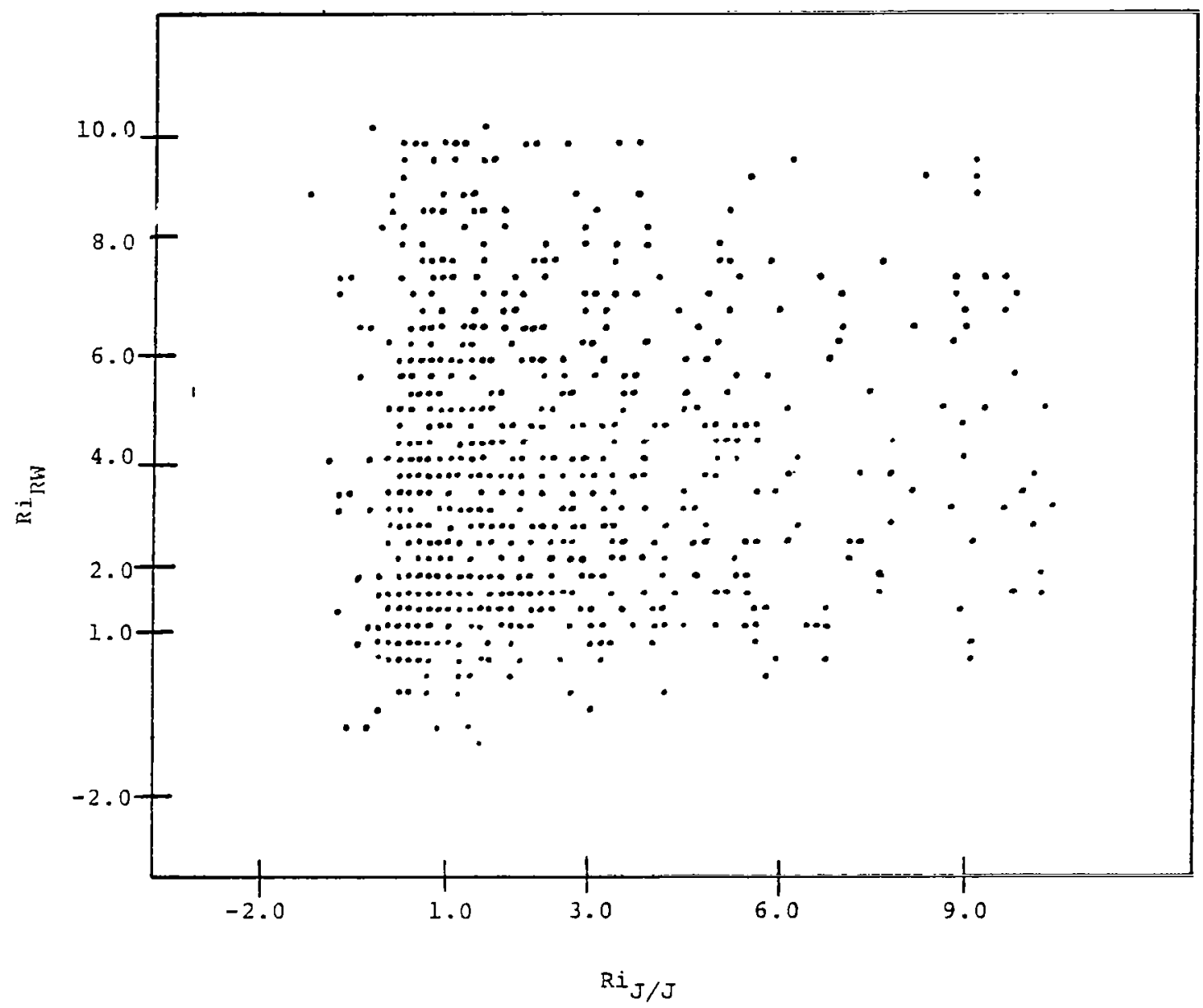

Figure 14. Correlation diagram relating the $\mathrm{RW}$ and $\mathrm{J} / \mathrm{J} \mathrm{Ri}$. The range of $\mathrm{Ri}$ was $-1<\mathrm{Ri}<10$ for purposes of illustration. 


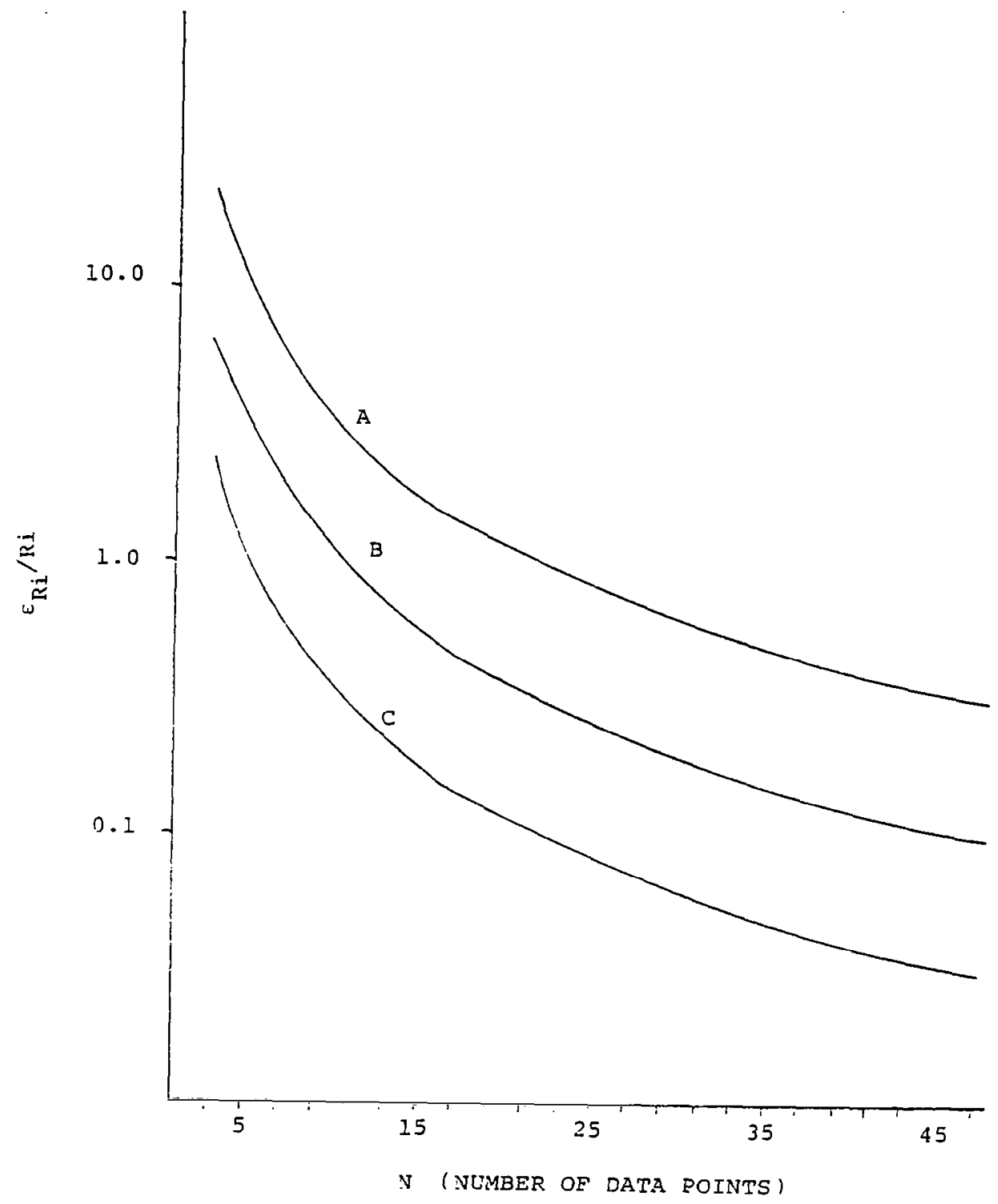

Figure 15. The dependence of the ratio of the error in the $\mathrm{Ri}, \varepsilon_{\mathrm{Ri}} / \mathrm{Ri}$, to the number of data 
static stability and moderate shear; and case $C$, strong static stability and strong shear. The relative accuracy of small Ri due to weak static stability and weak shear is relatively small compared to the more important turbulence associated with statically stable layers possessing strong shear (case $A)$. For the $J / J(N=21)$ it can be seen that for conditions of strong shear and static stability (case C) Ri can be calculated to within $10 \%$ error. The RW $(N=3)$ error, however, is the same order of magnitude as the Ri itself.

In addition to inadequate resolution, the following factors may contribute to the observed poor relationship between the $\mathrm{RW}$ and $\mathrm{J} / \mathrm{J}$ systems.

1. Synchronization. If the time lag in the flight times of the $\mathrm{J} / \mathrm{J}$ and $\mathrm{RW}$ balloons is too great, the relative "conjunctiveness" may be in question. While probably not an important factor for synoptic scale motions, it may be for mesoscale motions.

2. Spatial Differences. It is possible, as well, that the unavoidably different trajectories taken by the two balloons may be an additional source of error. Once again, the smaller the scale of motion under study, the more important this factor may be.

3. Improper (or Inappropriate) Choice of Vertical Grid Scale, $\Delta h$. As was discussed earlier in the text of this report, if the vertical differencing is too coarse the true vertical turbulent structure cannot be resolved. However, if too small, vertical differencing would filter out the important shear structure while at the same time it would overemphasize the contribution due to error.

4. Differences in $R W$ and $J / J$ Response and Tracking Accuracy. Differences in the response to wind perturbations by the balloons themselves and the discrepancies resulting from the different system tracking procedures should contribute to inconsistencies in the wind data. This error would, of course, be present in parameters calculated. using the wind data. Possible differences in temperature profiles should also be considered. 
The effects of poor synchronization and spatial differences have been a concern in previous research efforts. Specifically, concern over these two factors was a major element in the approach taken by Belmont, et al. (1966). Belmont attempted to compare the two systems by selectively removing all the Jimsphere data points but those corresponding to Rawinsonde points. Thus, this approach disregarded the differences in wind response and tracking accuracy between the FPS-16 J/J system and the RW system radar in an attempt to isolate the problems resulting from inadequate data resolution.

Serious problems caused by either of the first two factors should be expressed in comparisons between the basic meteorological variables measured by conjunctive RW-J/J flights. Figures 16, 17, and 18 show the correlation diagrams for "equal-level" temperature, horizontal wind amplitude and direction, respectively. The temperature shows a very high correlation while the horizontal wind vector shows somewhat less. The impressive temperature correlation suggests that inconsistencies are due more to the poorer Rawinsonde tracking accuracy than to problems resulting from synchronization or spatial differences.

\subsubsection{Static Stability and Shear}

The nature of the Richardson number suggests investigation of its component parts: the static stability, $\mathrm{N}_{\mathrm{B}}{ }^{2}$ and the shear magnitude, ||$\Lambda \mid$. When viewed in a physical context, distinctly different roles are revealed. That is, while large $|/ \Lambda|$ is generally associated with large static stability, large $\mathrm{N}_{\mathrm{B}}{ }^{2}$ along does not imply large shear. Re-examination of Figure 1 reveals that, in general, large values of $\mathrm{N}_{B}{ }^{2}$ exist for even small values of shear while the converse is not true. Thus, the most important factor, at the mesoscale, in determining the probability of the existence of turbulence within a given atmospheric layer, is the magnitude of the shear within the layer. Once it is determined what shear criterion is required for a given atmospheric layer, it may be possible to use Rawinsonde 


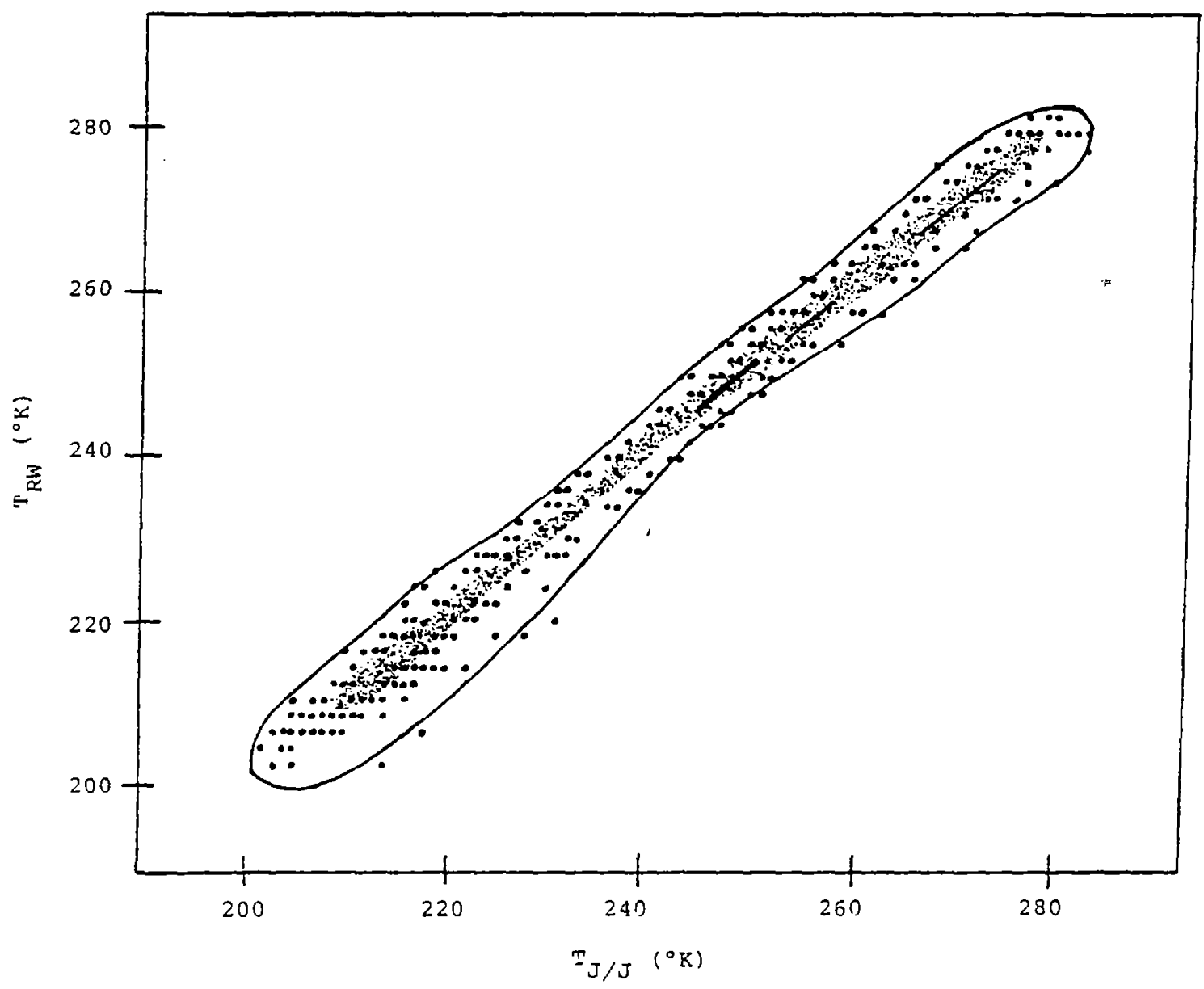

Figure 16. Correlation diagram comparing RW and $\mathrm{J} / \mathrm{J}$ temperatures at equal levels. The correlation coefficient is 0.997 . 


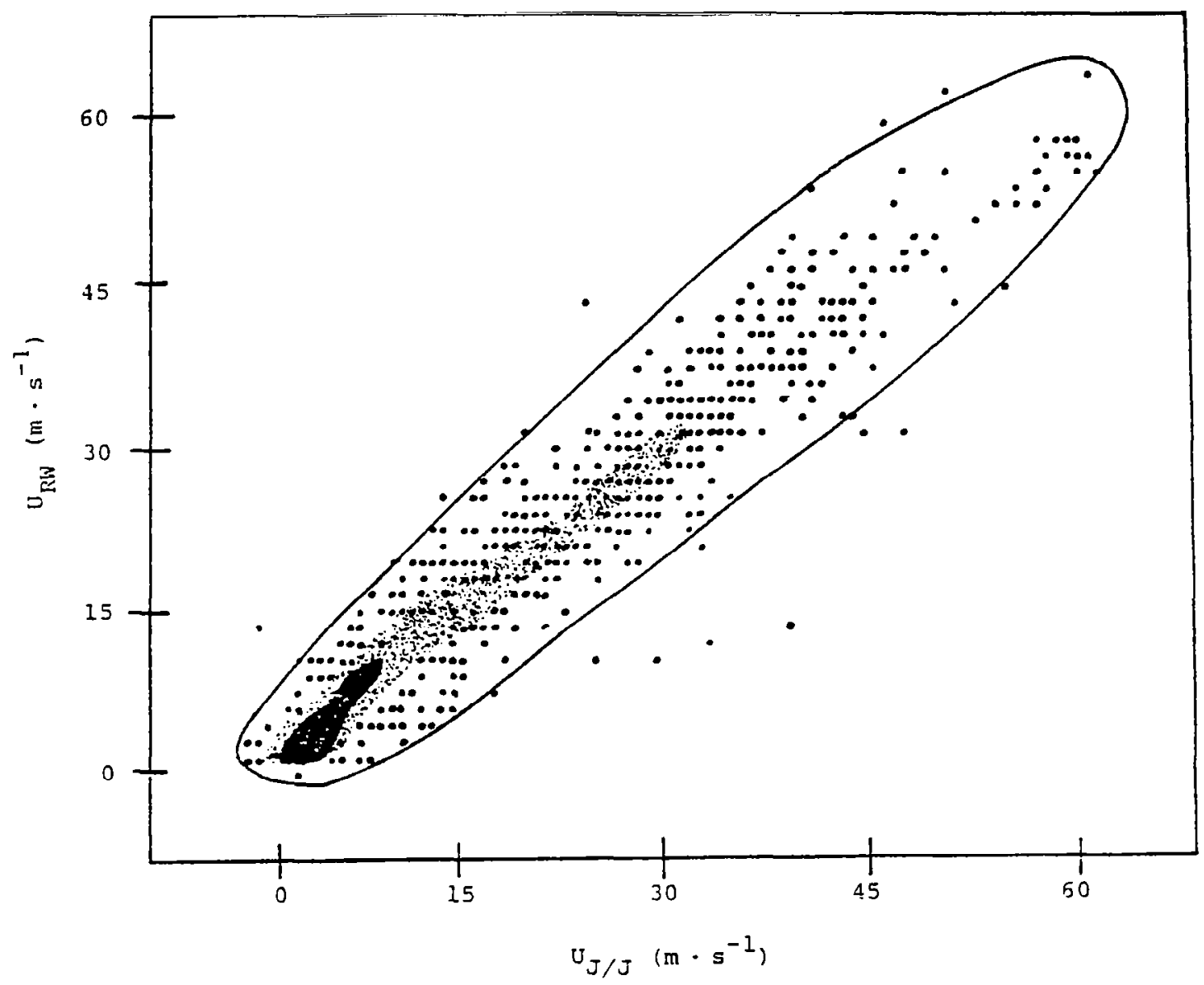

Figure 17. Correlation diagram comparing RW and $\mathrm{J} / \mathrm{J}$ horizontal wind amplitudes at equal levels. The correlation coefficient is 0.965 . 


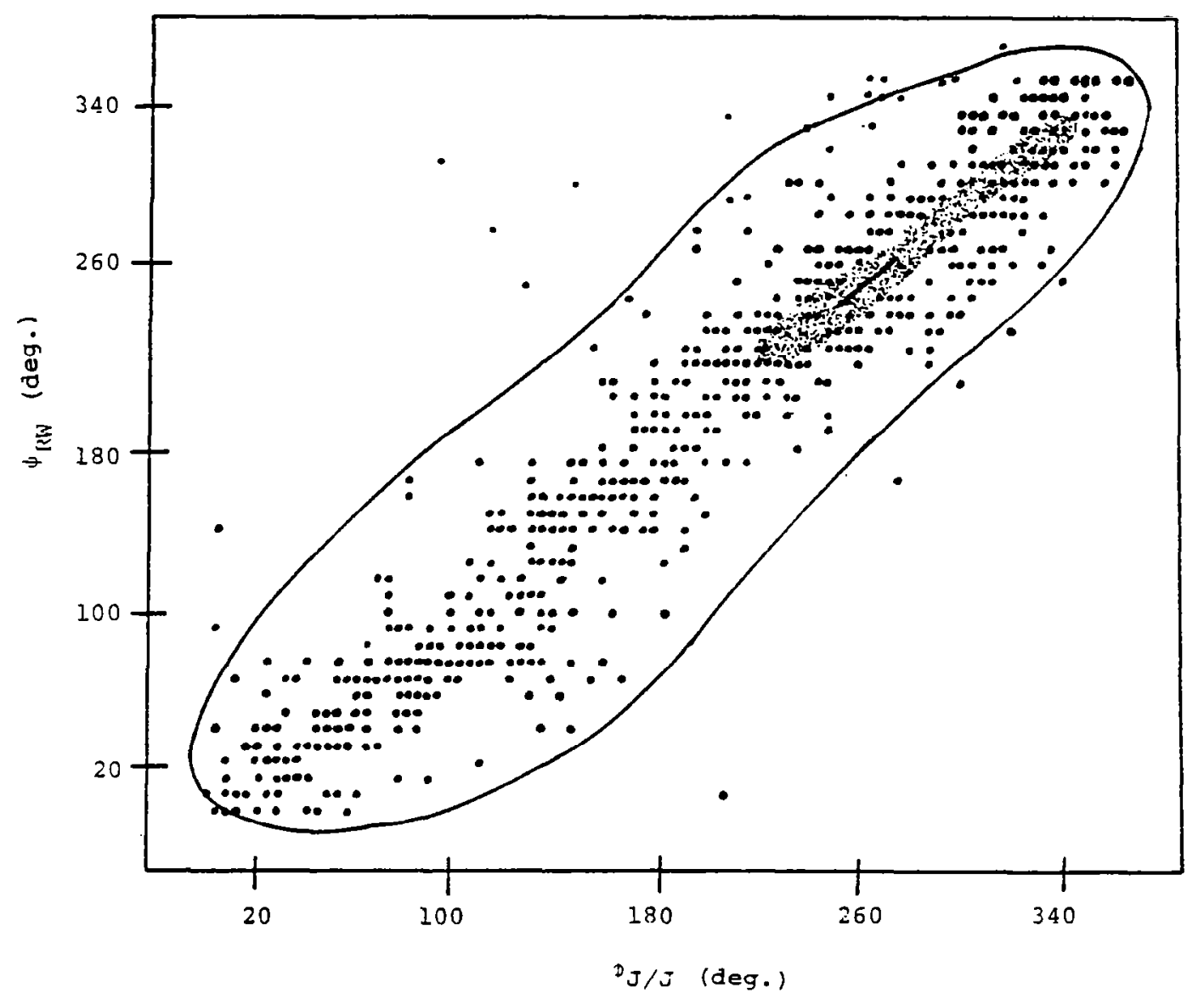

Figure 18. Correlation diagram comparing $\mathrm{RW}$ and $\mathrm{J} / \mathrm{J}$ wind direction at equal levels. The correlation coefficient is 0.672 . 
shears with the aid of $\mathrm{J} / \mathrm{J}$ information to infer the existence of turbulence.

3.3.2 Turbulent Structure of Detailed Vertical Profiles of the Horizontal wind

In examining the statistical characteristics of numerous height profiles of the horizontal wind vector measured by the Jimsphere system, certain workers (e.g., Essenwanger, 1963; Essenwanger and Reiter, 1969) have been able to establish the relationship between detailed wind profiles and isotropic turbulence. It was determined that the vector shear amplitude obeys the relationship:

$$
|\Delta \mathbb{W}|=a_{0}(\Delta h)^{a_{1}} ;
$$

where

$\Delta \mathrm{h}$ : interval of calculation,

$|\Delta \mathbb{V}|$ : amplitude of the horizontal velocity vector difference through $\Delta h$,

$a_{\circ}$ : empirical constant fit coefficient, and

$a_{1}$ : empirical constant fit exponent.

This relationship is observed to have a standard deviation which is a linear function of $|\Delta \mathbb{V}|$.

where

$$
\sigma|\Delta v|=A_{0}+A_{1}|\Delta| \mathbf{V} \mid ;
$$

$$
\begin{gathered}
\sigma_{|\Delta \mathbb{V}|} \text { : standard deviation of }|\Delta \mathbb{V}| \text { and } \\
\mathrm{A}_{0^{\prime}} \mathrm{A}_{1} \text { : empirical constant fit coefficients. }
\end{gathered}
$$

When the empirical results given by Equation (10) are related to the theories developed by earlier workers (e.g., Tartarski, 1961; Kolmogorov, 1941; Obukov, 1941) a value of $a_{1}=1 / 3$ is predicted for shear layers possessing isotropic turbulence. This value for $a_{1}$ is in agreement with observations of "mean extreme shears"* (Figure 19, Essenwanger and Reiter, 1969). This consistency between theory and the $\mathrm{J} / \mathrm{J}$ horizontal wind profiles is a result of the J/J system's inherent ability to resolve atmospheric mesoscale structure. The value of a turns out to be about 1.22 for mean extreme vector shears. It can be

${ }^{\star}$ A statistical device first employed by Essenwanger, 1963. 


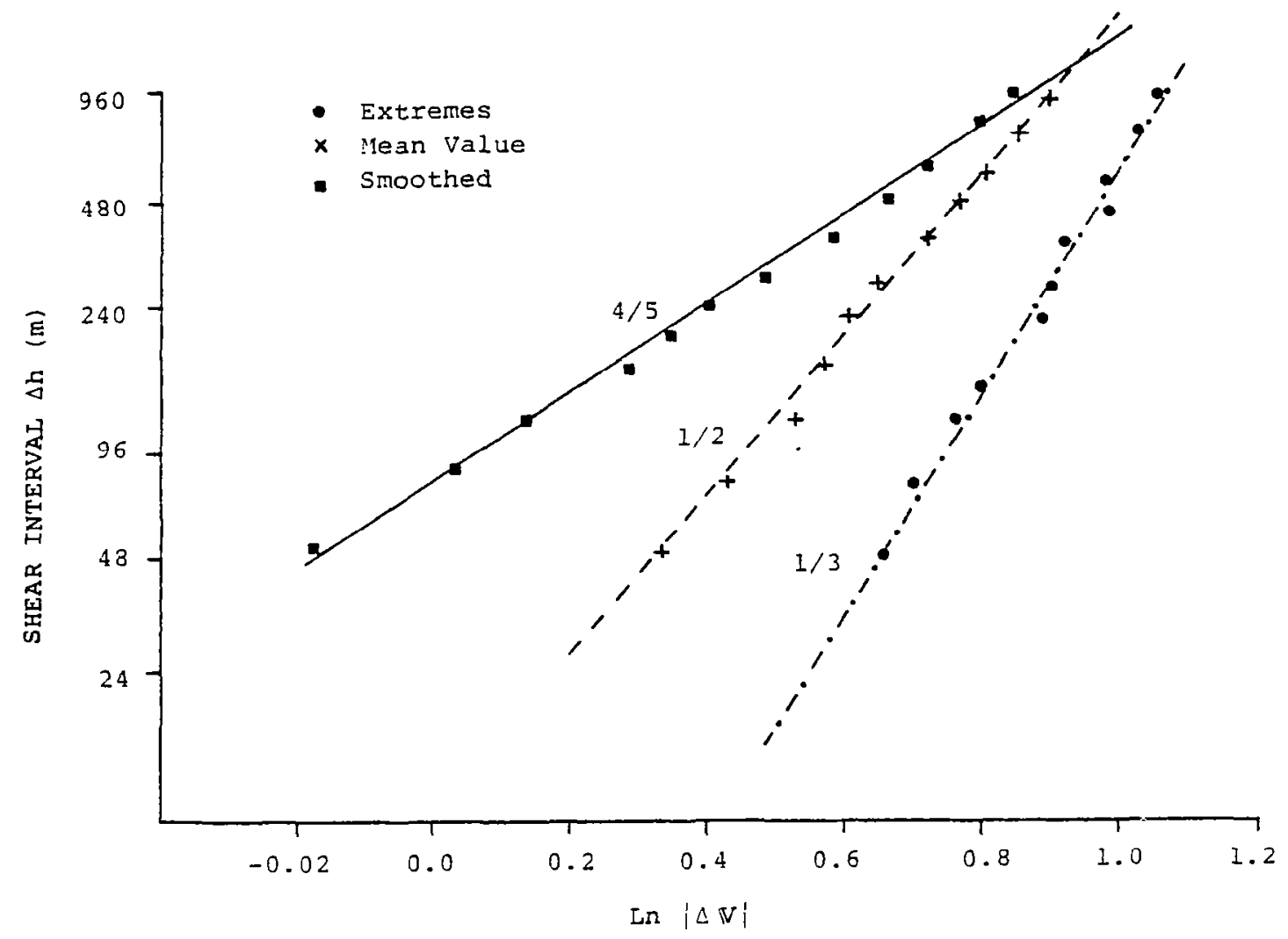

Figure 19. Dependence of the natural log of the vector shear amplitude on the interval of calculation for mean extreme shears, mean shears, and smoothed horizontal wind profiles; sketched from Essenwanger and Reiter (1969). 
shown that for the interval $\Delta \mathrm{h}=500 \mathrm{~m}$ a vector shear amplitude of $0.020 \mathrm{~s}^{-1}$ satisfies Equation (10). Thus, a J/J wind profile which yields a vector shear amplitude of $0.020 \mathrm{~s}^{-1}$ or greater calculated through an interval of $\Delta \mathrm{h}=500 \mathrm{~m}$ should be turbulent. No information can be assumed on its intensity. The relative intensity can only be known if the amplitude of the breaking wave is obtained (Atlas and Metcalf, 1970) or if the mesoscale dynamics are considered. While it may be possible to detect probable turbulent layers in the free atmosphere using the $\mathrm{J} / \mathrm{J}$ system by application of Equation (10), it remains to be seen whether the RW system can similarly be employed. It was shown earlier that no reliable relationship exists between $J / J$ and $R W$ but the shears may be more clearly related.

To further examine this point, consider Figures 20 and 21 which illustrate vertical profiles of $\mathrm{J} / \mathrm{J}$ and $R W$ vector shears. According to the criterion above applied to the $\mathrm{J} / \mathrm{J}$ profile, Figure 20, turbulent conditions should be expected at two or three layers averaging several hundred meters in thickness. Figure 21, the corresponding $R W$ shear profile, shows generally smaller values of shear with no layers above $0.020 \mathrm{~s}^{-1}$, but several relative maxima are evident at approximately the same levels as those of the J/J profile. Consider Figure 22. The diagonal line is the approximate intersection of maximum frequency. The equation of this line is:

$$
|\Lambda|_{R W}=0.001+0.5|\Lambda|_{\mathrm{J} / \mathrm{J}}
$$

Hence, if Equation (12) was strictly true, a Rawinsonde passing through a $500 \mathrm{~m}$ layer for which the $\mathrm{J} / \mathrm{J}$ would sense a shear of $0.020 \mathrm{~s}^{-1}$ would detect a shear of $0.011 \mathrm{~s}^{-1}$.

Applying this relationship to an individual case, consider Figures 23 and 24. Figure 23 indicates, by this 


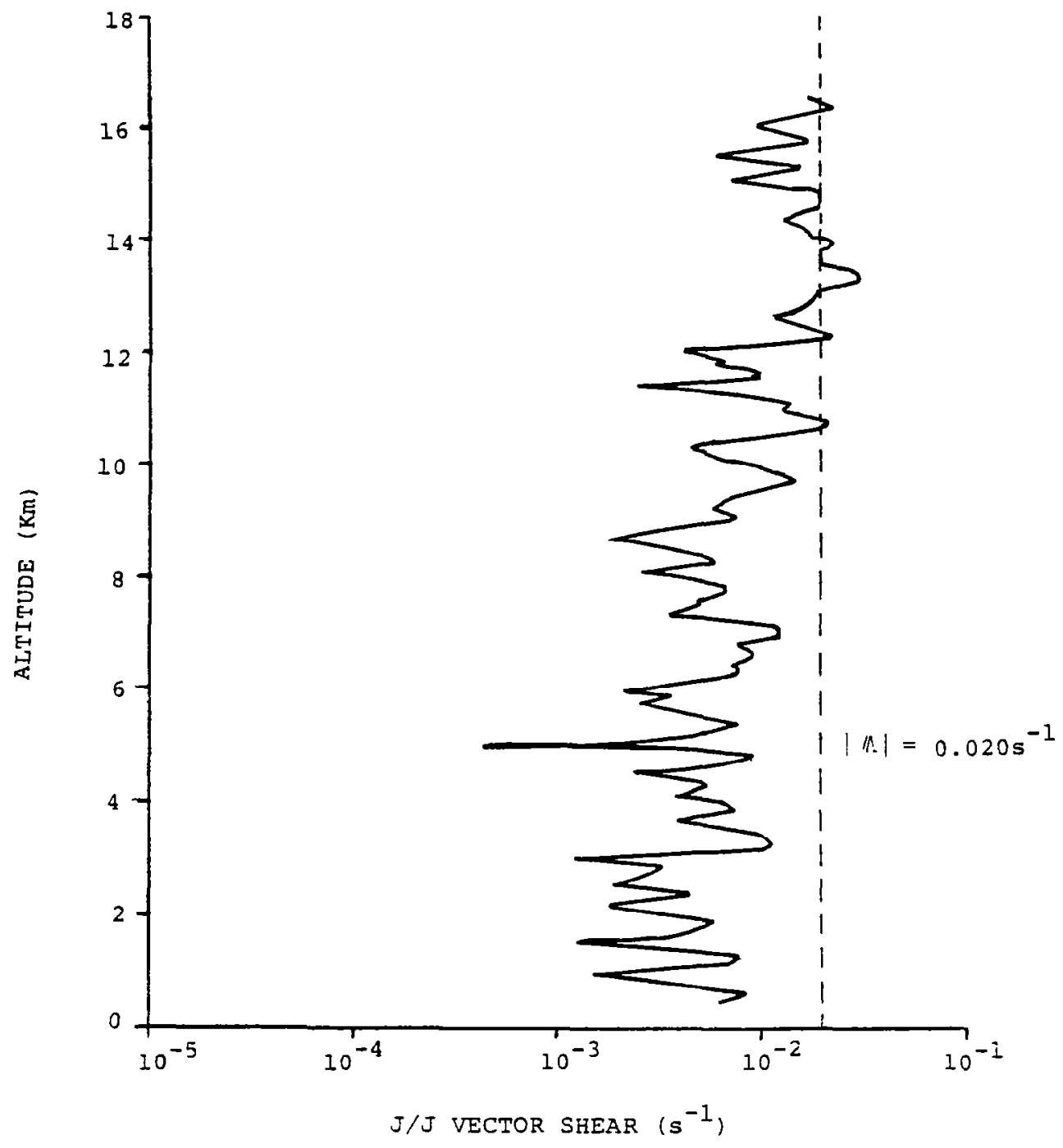

Figure 20. Vertical variation of the vector shear magnitude for the $\mathrm{J} / \mathrm{J}$ flight of $1345 \mathrm{z} 16$ October 1970 . 


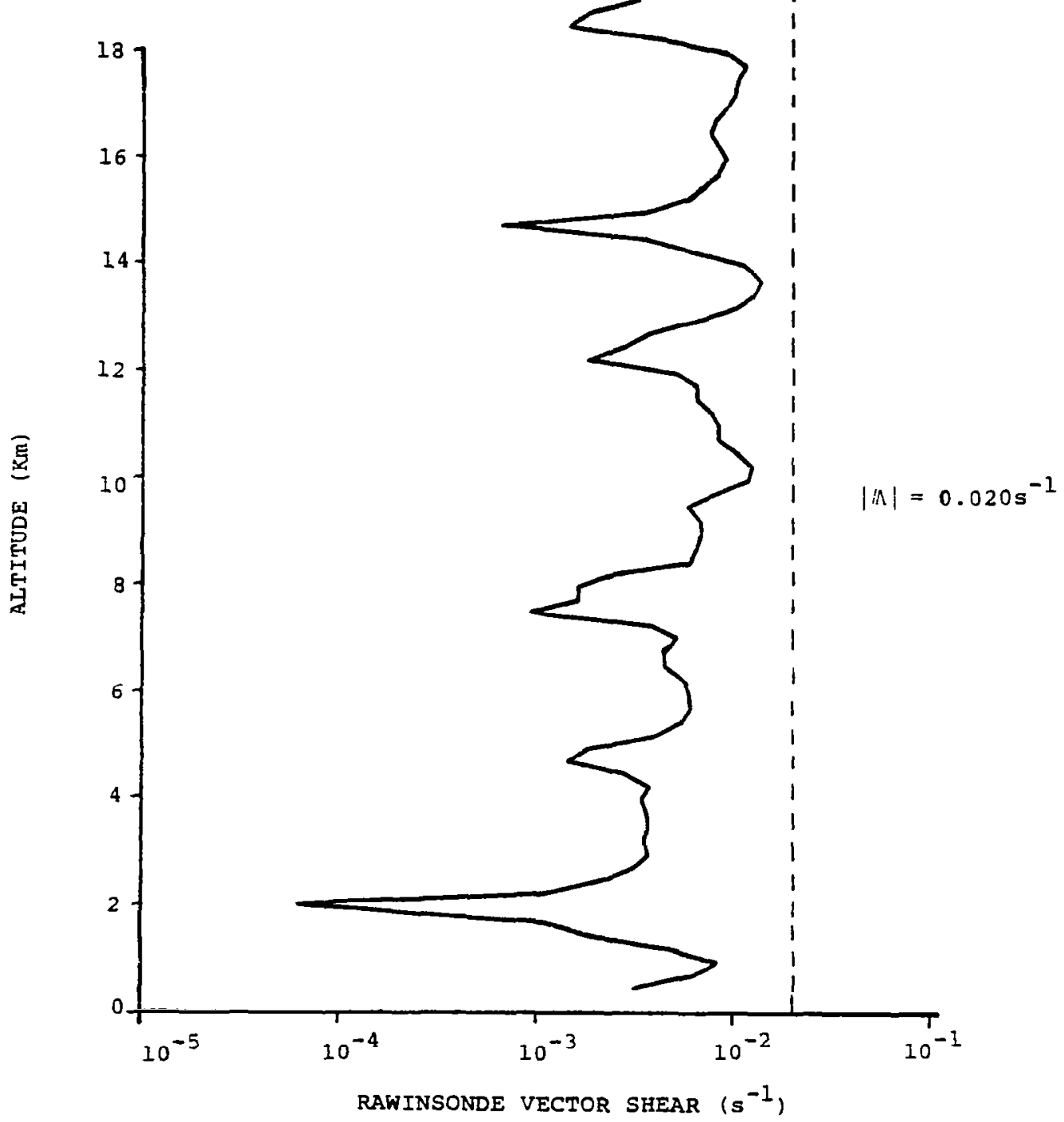

Figure 21. Vertical variation of the vector shear magnitude for the $R W$ flight of $1015 \mathrm{z}$ 16 October 1970 . 


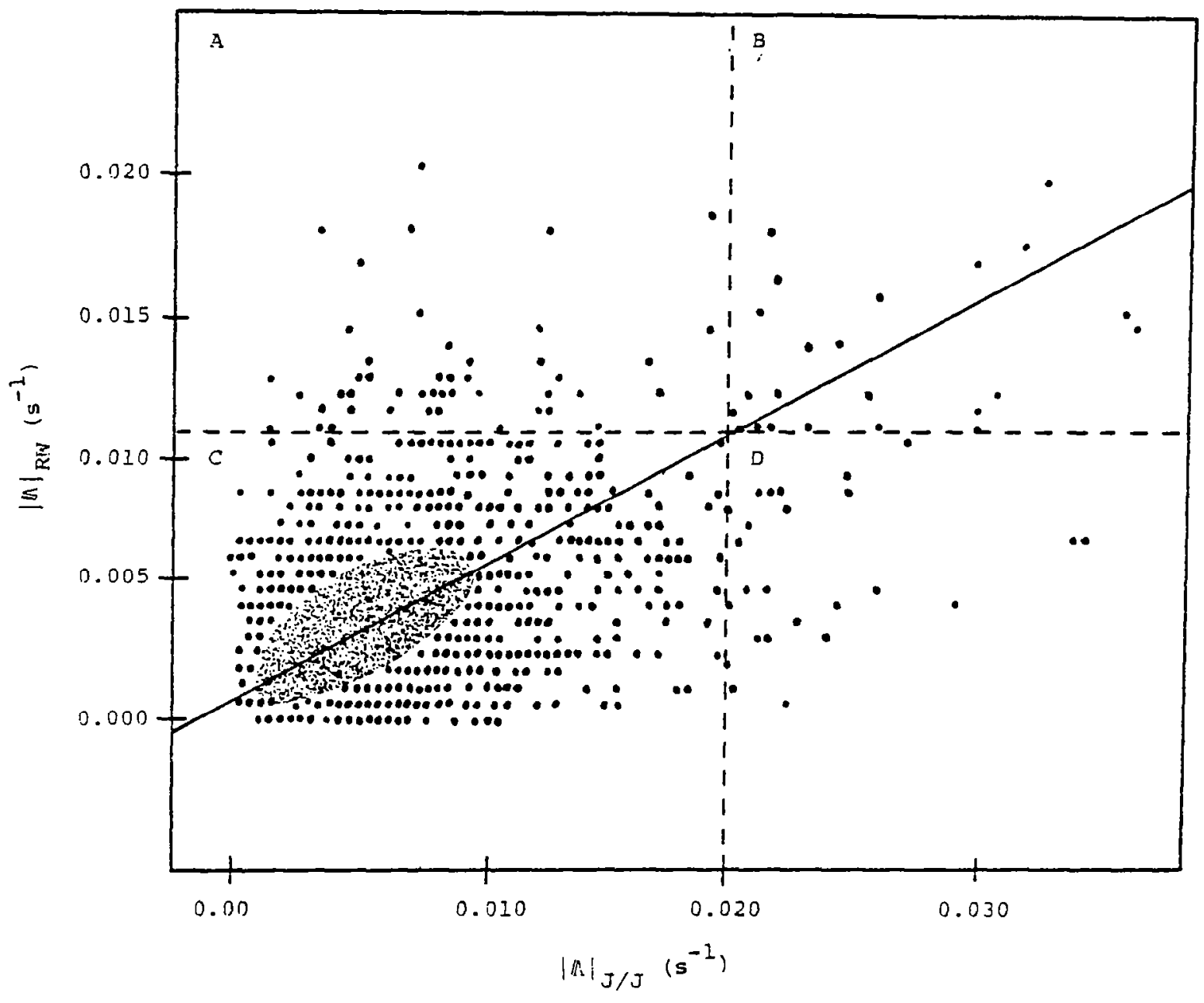

Figure 22. Correlation diagram comparing $\mathrm{J} / \mathrm{J}$ and $\mathrm{RW}$ vector shear amplitudes. 


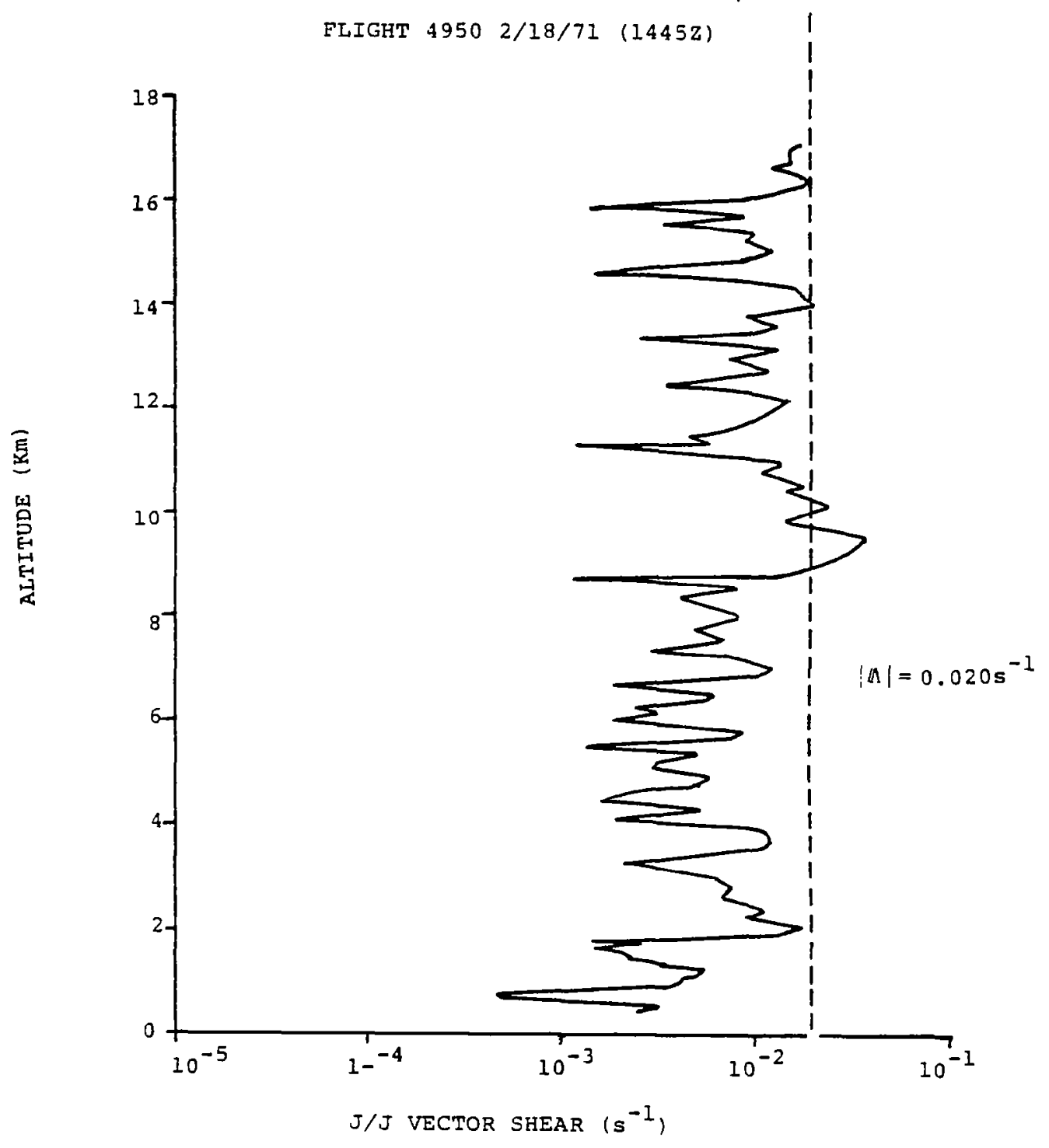

Figure 23. Vertical variation of the $\mathrm{J} / \mathrm{J}$ vector shear amplitude on the $1445 \mathrm{z} 18$ February 1971. 


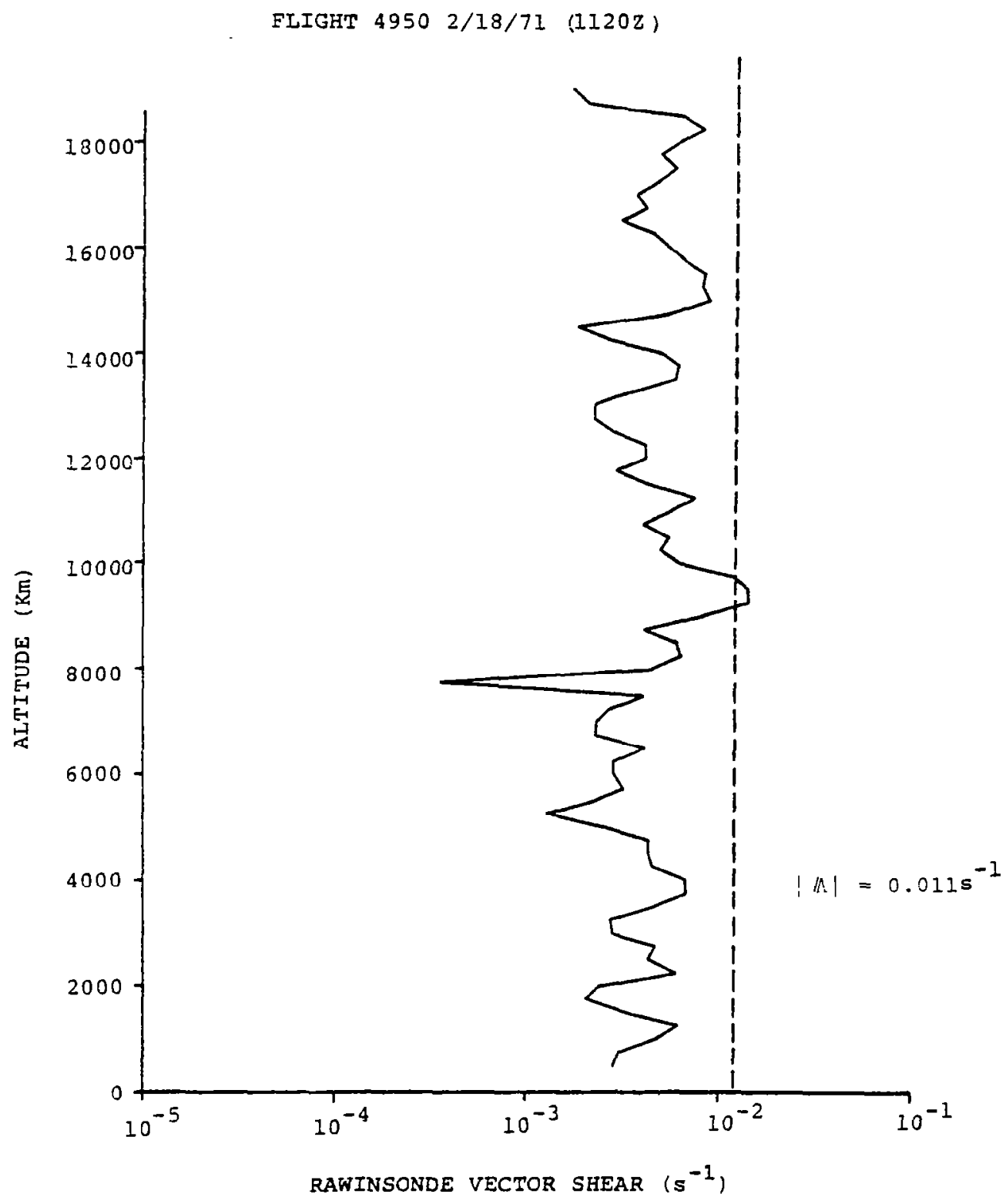

Figure 24. Vertical variation of the RW vector shear amplitude on 1120218 February 1971. 
reasoning, a significantly turbulent layer nearly $\mathrm{I} \mathrm{Km}$ in depth at an altitude of about $10 \mathrm{Km}$. Using Equation (12) to "enhance" the RW shear, Figure 24 reveals the turbulent layer seen in Figure 23. Results analogous to this were obtained in the observational study of Glover, et al. (1969). However, in that study, the depth of the interval, $\Delta h$, over which the shear layer was calculated was allowed to vary and the center of the shear layer was chosen so that the shear was maximized. If Equation (12) were sufficiently general, layers for which $|/ \Lambda|_{\mathrm{RW}} \geq 0.011 \mathrm{~s}^{-1}$ might then be considered as containing isotropically turbulent motion.

Figure 22 has been divided into four regions according to $\mathrm{J} / \mathrm{J}$ shear criterion given by Equation (12) which has been shown to enhance the RW sensing capacity. Regions A, B, C, and $D$ are defined in Table II. The J/J detected 50 cases for which the shear exceeded $0.020 \mathrm{~s}^{-1}$; assume that the $\mathrm{J} / \mathrm{J}$ establishes the standard to which the RW is to be compared. The RW sensed 2 shear layers with shears greater than $0.020 \mathrm{~s}^{-1}$ and 74 for which it exceeded $0.011 \mathrm{~s}^{-1}$. However, for the former only 1 of the 2 agreed with the $\mathrm{J} / \mathrm{J}$ while for the latter there were 24 . The results on the basis of assumed correct $\mathrm{J} / \mathrm{J}$ observations can be summarized in Table III. There is a relatively impressive improvement in the sensitivity of the Rawinsonde at the expense of about a $30 \%$ decrease in accuracy. However, when viewed in absolute terms it is somewhat less impressive. Even when using the "enhanced sensitivity" shear criterion, the RW detects less than one of two (0.480) apparently turbulent shear layers. As well, the chances are nearly two of three that a given shear layer has been incorrectly identified by the Rawinsonde as satisfying the conditions necessary for turbulence. This latter problem of "overlapping" or "blurring" is evident in the RW system due to its poor vertical resolution. Thus, the existence of a turbulent shear layer cannot be reliably and unambiguously inferred using a single station RW vertical wind profile. 


\section{TABLE II}

Definitions of regions in Figure 22
$A\left\{\begin{array}{l}|\mathbb{M}|_{\mathrm{RW}}>0.011 \mathrm{~s}^{-1} \\ |\mathbb{M}|_{\mathrm{J} / \mathrm{J}}<0.020 \mathrm{~s}^{-1}\end{array}\right.$
$B\left\{\begin{array}{l}|\Lambda|_{\mathrm{RW}}>0.011 \mathrm{~s}^{-1} \\ |\Lambda|_{\mathrm{J} / \mathrm{J}}>0.020 \mathrm{~s}^{-1}\end{array}\right.$

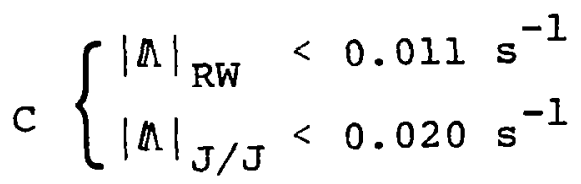
$D\left\{\begin{array}{l}|M|_{\mathrm{RW}}<0.011 \mathrm{~s}^{-1} \\ |M|_{\mathrm{J} / \mathrm{J}}>0.020 \mathrm{~s}^{-1}\end{array}\right.$ 
TABLE III

Summary of RW Shear Layer Sensing Ability and Accuracy Relative to the $\mathrm{J} / \mathrm{J}$ System

Shear Criterion

$$
\begin{aligned}
& 0.020 \mathrm{~s}^{-1} \\
& 0.011 \mathrm{~s}^{-1}
\end{aligned}
$$

Sensitivity $[R W] /[\mathrm{J} / \mathrm{J}]$

$1 / 50$

$(0.020)$

$24 / 50$

$(0.480)$
Accuracy

$1 / 2 \quad(0.500)$

$24 / 74 \quad(0.365)$ 


\subsubsection{The Diagnostic Richardson Number}

An approach, most recently investigated by M.J. Oard (1974) uses synoptic scale changes in meteorological variables to obtain a rough measure of the time required for synoptic scale regions of the atmosphere to reach the critical Richardson number $\left(R i_{c}\right)$ necessary for the onset of clear air turbulence. Since Rawinsonde data is used as input, development of this technique represents a way in which the existing operational Rawinsonde network could eventually be applied to CAT probability forecasting.

The Diagnostic Richarson Number Tendency (DRT) method has been applied in a diagnostic study (Oard, 1974) of a well-documented outbreak of CAT over the Northeastern U.S. (Reed and Hardy, 1972). This technique correctly identified regions which showed a high propensity for CAT development as was later verified by aircraft encounters and sensitive radar. At its present stage of development, the DRT method is well suited to the special nature of the synoptic processes responsible for this particular type of CAT outbreak. It may also be applicable to CAT associated with mountain waves. It may not be able to resolve local areas of turbulence caused directly by unstable boundary layers or thunderstorms.

The method essentially senses certain changes in the atmosphere at the synoptic scale responsible for the development of statically stable layers with strong vertical shear. Within these synoptic scale shear layers would be the more intense mesoscale shear layers supporting the CAT producing mechanisms which are a manifestation of unstable $\mathrm{K}-\mathrm{H}$ shear instability. The DRT method as formulated by Oard (1974) is best suited for cases when the bulk of the vertical wind shear at the synoptic scale is due to thermal wind balance, specifically frontal and other highly baroclinic zones. 


\section{4 CONCLUSION}

It was hoped that the information contained in vertically detailed $\mathrm{J} / \mathrm{J}$ profiles might be applied to the currently operational RW system to enable this system to be employed in CAT detection or forecasting. Such information would be of great value to the airline industry contributing to increased safety and passenger comfort. Through consideration of what is known about the physical and statistical nature of CAT, the CAT mechanism, and detailed vertical profiles of meteorological variables, it was determined that a relationship does exist between $J / J$ and $R W$ shears. Unfortunately, this particular relationship lacks sufficient reliability to be applied in general.

It would appear that the RW cannot be used to detect the existence of CAT in a single vertical profile, let alone its intensity. Possible factors include the coarse vertical resolution and an inadequate tracking system. These inadequacies appear to be more than what can be overcome by the supplemental information supplied by conjunctive $\mathrm{J} / \mathrm{J}$ soundings. Although detecting CAT by using a single RW vertical sounding appears unreliable at best, the development of the DRT method represents a potential use for the operational RW network. 
Acheson, D.J., 1976: On Over-Reflexion. J. Fluid Mech., 77, $433-472$.

Atlas, D., et al., 1970: The Birth of "CAT" and Microscale Turbulence. J.Atm. Sci., 27(6), 908-913.

Atlas, D. and J.I. Metcalf, 1970: The Amplitude and Energy of Breaking Kelvin-Helmholtz Waves and Turbulence. U. of Chicago and Illinois Inst. of Technology Tech. Rpt. No. $19,33 \mathrm{pp}$.

Beckwith, W. B., 1972: Airline Meteorology Today. Reprinted from Technology Review, edited at the Massachusetts Institute of Technology, $9 \mathrm{pp}$.

Belmont, A.D., et al., 1966: Comparison of Jimsphere and Rawinsonde Wind Shears. Control Data Corp., Minneapolis, Minnesota $(\mathrm{AD} 6508-6) \cdot 100 \mathrm{pp}$.

Boucher, R.J., 1970: CAT at a Subsidence Inversion: A Case Study. J.Appl. Meteor., 9 (3), 534-537.

- 1973: Mesoscale History of a Small Patch of Clear Air Turbulence. J. Appl. Meteor., 12(5), 814-821.

Bretherton, F.P., 1969: Momentum Transport by Gravity Waves. Q.J. Roy. Meteor. Soc., 95 $(404), 213-243$.

DeMandel, R.E. and S.J. Krivo, 1968: Capability of the FPS-16 Radar/Jimsphere System for Direct Measurements of Vertical Air Motions, NASA/CR-61232, 47 pp.

Essenwanger, O.M., 1963: On the Derivation of Frequency Distributions of Vector Shear Values for Small Shear Intervals. Geofis. Pura. Appl., 56, 216-224.

Essenwanger, O.M. and E.R. Reiter, 1969: Power Spectrum, Structure Function, Vertical Wind Shear, and Turbulence in Troposphere and Stratosphere. Arch. Met. Geoph. Biokl., Ser. A, 18, 17-24.

FichtI, G.H., 1971: The Response of Balloon and Falling sphere Wind Sensors in Turbulent Flows, NASA TN D-7049, 26 pp.

Glover, K.M., et al., 1969: Simultaneous Radar, Aircraft and Meteorological Investigations of Clear Air Turbulence. J.Appl. Meteor. , $8(4), 634-640$. 
Hicks, J.J., 1969: Radar Observations of a Gravitational Wave in Clear Air Near the Tropopause Associated with CAT. J. Appl. Meteor., 8 $(4), 627-633$.

Hines, C.O., 1968: Some Consequences of Gravity-Wave Critical Layers in the Upper Atmosphere. J. Atmos. and Terres. Phys., 30. $837-843$.

Howard, L.M., 1961: Note on a Paper of John W. Miles. J. Fluid Mech. , 10, 509-512.

Jordan, A.R., 1972: Atmospheric Gravity Waves from Winds and Storms. J.Atm. Sci., 29(3), 445-456.

Kogan, Z.N., 1973: Instability of Internal Waves in stratified Jet Streams. Trans. from Meteorologiya i Gidrologiya, (5), 12-2I NTIS (AD-761373).

Kolmogorov, A.N., 1941: Dissipation of Energy in Locally Isotropic Turbulence. Doklady Akad. Nauk SSR, 32, p..77.

Lalas, D.P., et al., 1976: The Destabilizing Effect of the Ground on Kelvin-Helmholtz Waves in the Atmosphere. J. Atm. Sci. 33(1), 59-69.

Iindzen, R.S., 1974: Stability of a Helmholtz Velocity Profile in a Continuously stratified, Infinite Boussinesq FluidApplications to Clear Air Turbulence. J.Atm. Sci., 31(6), 1507-1514.

Lindzen, R.S. and A.J. Rosenthal, 1976: On the Instability of Helmholtz Velocity Profiles in stably stratified Fluids When a Lower Boundary is Present. J. Geophys. Res., 81 (9), 1561-1571.

Luers, J.K. and C.D. MacArthur, 1972: Ultimate wind Sensing Capabilities of the Jimsphere and Other Rising Balloon Systems, NASA CR-2048, 111 pp.

Miles, J.W., 1961: On the Stability of Heterogeneous shear Flow. J. Fluid Mech. , $10,496-508$.

Oard, M.J., 1974: Application of a Diagnostic Richardson Number Tendency to a Case study of CAT. J. Appl. Meteor., 13(7), $771-777$.

Obukhov, A.M., 1941: On the Distribution of Energy in the Spectrum of Turbulent Flow. Diklady Akad. Nauk SSR, 32, p. 103.

Range Commanders Council Document 110-77, 1977: Committee of the Meteorological Group, Secretariat Range Commanders Council, White Sands Missile Range, NM 88002, 19 pP. 
Reed, R.J. and K.R. Hardy, 1972: A Case Study of Persistent Intense Clear Air Turbulence in an Upper Level Frontal zone. J.Appl. Meteor., II(3) 541-549.

Reiter, E.R., 1969: The Nature of Clear Air Turbulence: A Review; in Clear Air Turbulence and Its Detection, $Y .-H$. Pao and A. Goldburg editors, Plenum Press, N.Y., 7-33.

Reiter, E.R. and P.F. Lester, 1968: Richardson's Number in the Free Atmosphere. Arch. Net. Geoph. Biokl., Ser. A, 17, $1-7$.

Scoggins, J.R., 1967: Sphere Behavior and the Measurement of Wind Profiles. NASA TN D-3994, 53 pp.

Scoggins, J.R. and M. Armendariz, 1969: On the Measurement of Winds by the AN/FPS-16 Radar/Spherical Balloon Method. J. Appl. Meteor. , 8(3), 449-452.

Stoeffler, R.C. and J.W. Clark, 1970: Further Research on Instabilities in Atmospheric Flow Systems Associated with Clear Air Turbulence. United Aircraft Corp. Rpt. J910563-14.

Susko, M. and W.W. Vaughan, 1968: Accuracy of Wind Data Obtained by Tracking a Jimsphere Wind Sensor Simultaneously with Two FPS-16 Radars, NASA TM X-53752, 43 pp.

Tartarski, V.I., 196I: Wave Propagation in a Turbulent Medium. McGraw-Hill, New York, 211 pp.

Vinnichenko, N.K. and T.A. Dutton, 1969: Empirical Studies of Atmospheric Structure and Spectra in the Free Atmosphere. Radio Sci., 4 (12), 1115-1126. 
TECHNICAL REPORT STANDARD TITLE PAGE

\begin{tabular}{|l|l|}
\hline $\begin{array}{l}\text { 1. } \\
\text { NEPORT NO. }\end{array}$ & 2. GOVERNMENT ACCESSION NO. \\
\hline TITLE AND SUBTITLE & $\begin{array}{l}\text { Prediction and Monitoring of Clear Air Turbulence: An } \\
\text { Evaluation of the Applicability of the Rawinsonde System }\end{array}$ \\
\hline 7. AUTHOR(S) \\
John L. Keller
\end{tabular}

3. RECIPIENT'S CATALOG NO.

5. REPORT DATE

December 1978

6. PERFORMING ORGANIZATION COIDE

8. PERFORMING ORGANIZATION REPOR T \#

10. WORK UNIT NO.

$\mathrm{M}-270$

11. CONTRACT OR GRANT NO.

NAS8-32111

13. TYPE OF REPOR $i$ \& PER 100 COVERED

15. SUPPLEMENTARY NOTES

Prepared under the technical monitorship of the Atmospheric Sciences Division, Space Sciences Laboratory, Science and Engineering, NASA/Marshall Space Flight Center

i6. ABSTRACT

Results from an investigation of the applicability of Rawinsonde data for either detection or prediction of clear air turbulence (CAT) are discussed. The mechanism currently believed responsible for the development of CAT is reviewed. Since previous studies have determined that the most significant factor for the existence of turbulent layers is the magnitude of the vertical shear, certain theoretically derived shear criteria are applied to statistical and diagnostic comparisons of R awinsonde and Jimsphere/Jimsonde conjunctive vertical profiles. It is determined that, apparently because of its inherently inadequate wind tracking ability and limited vertical resolution, the Rawinsonde system cannot reliably be used as a CAT detector in a "single-station" sense. Information on tendencies of meteorological parameters important at the synoptic scale for the development of CAT layers, however, may be extractable from a horizontal grid of Rawinsonde ascents by using the "Diagnostic Richardson Number" technique.

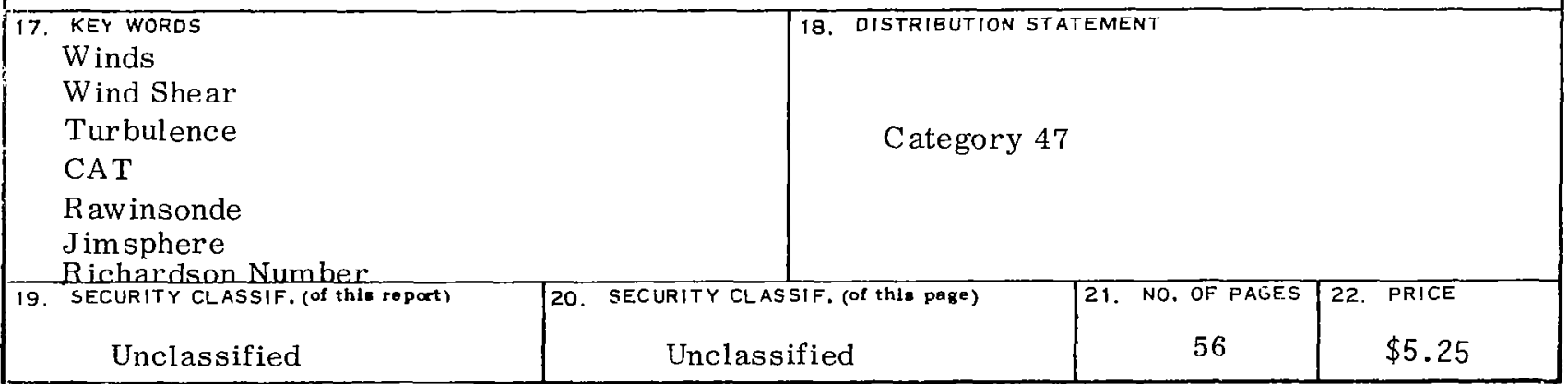

